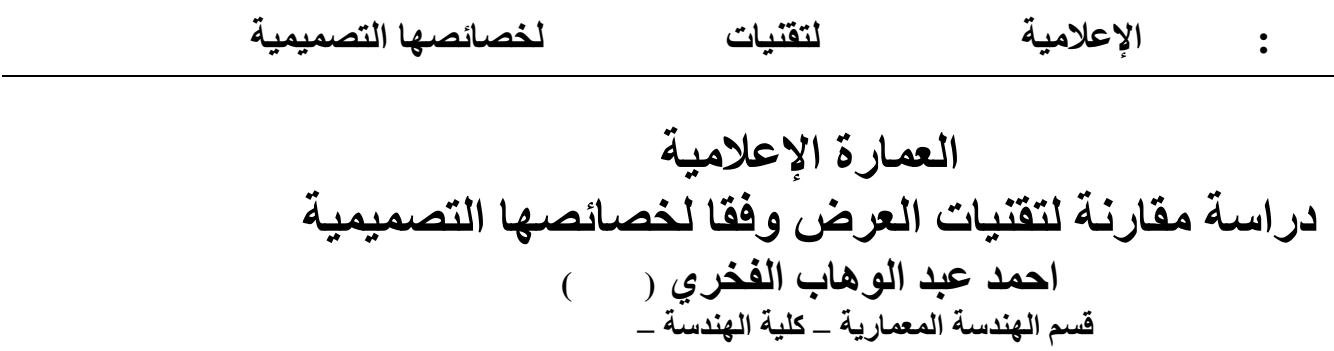

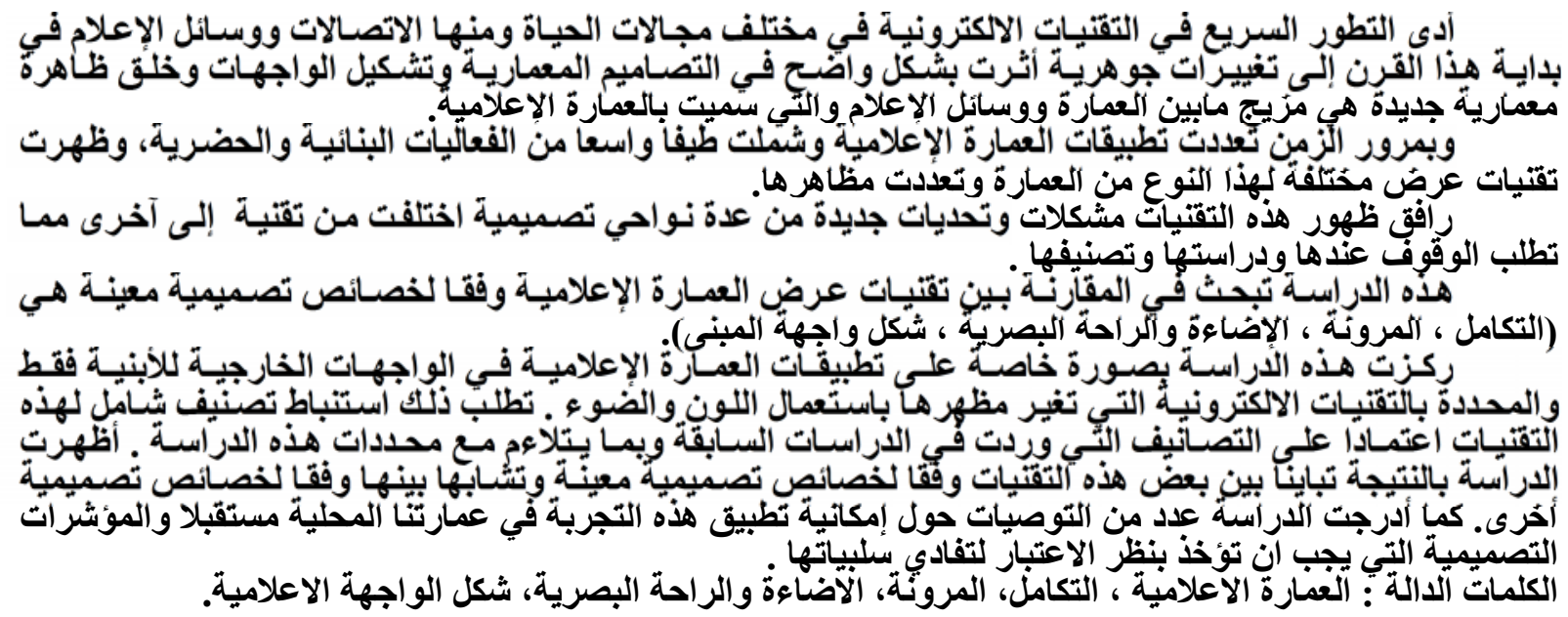

\title{
Media Architecture \\ A Comparative Study of Display Technologies According to Their Design Characteristics
}

Ahmed A. Alfakhry (Lecturer)

Department of Architecture, College of Engineering, University of Mosul

\begin{abstract}
The vast development of electronic technologies in various fields of life, including communications and media at the beginning of this century led to fundamental changes , affected clearly in architectural design and formation of building facades and create a completely new architectural phenomenon which is a mix between architecture and media . This hybrid phenomenon was named as Media Architecture.

Over time, Media Architecture involved in numerous applications and had a wide range of architectural and urban activities, at the same time, different display technologies and numerous manifestations were appeared.

The emergence of these display technologies were accompanied by new specific problems and challenges from several design aspects, these challenges were different from one display technology to another which required more studies and researches.

This study deals with comparing different display technologies according to specific design characteristics (integration, flexibility, lighting and visual comfort , and media facade shape ). This study concentrated particularly on the application of Media Architecture in exterior building facades and electronic display technologies that change their appearance by use of color and light, this required a comprehensive classification to these technologies depending on the previous studies in line with the determinants of this study. The study showed variations between some of these display technologies in accordance with the design characteristics, and similarities between others. Number of recommendations was drawn in this study considering the possibility of applying this approach in our traditional architecture in future, and design indices that must be taken into consideration in order to avoid their disadvantages.

Key words : Media architecture, Integration, Flexibility, lighting and visual comfort, media facades shape.
\end{abstract}


:

شهد المشهد الحضري في المدن الكبيرة على مدى العقد الماضـي تغير ات جوهريـة تحت تأثير العولمـة والتجـارة

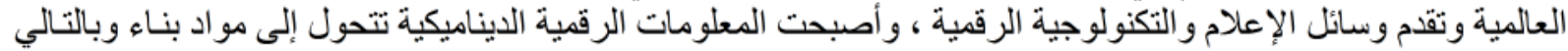

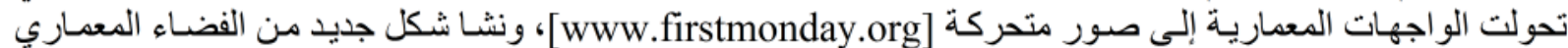

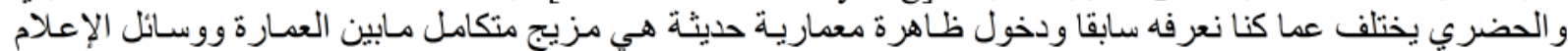
و الاتصالات الحديثة والتي سميت فيما بعد بالعمارة الإعلامية.

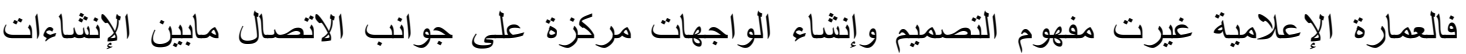

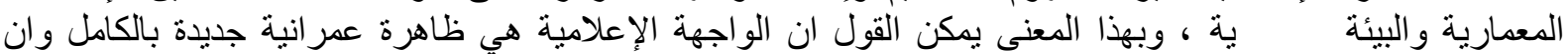

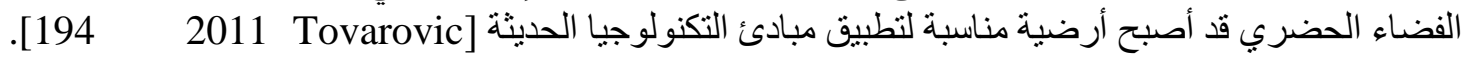

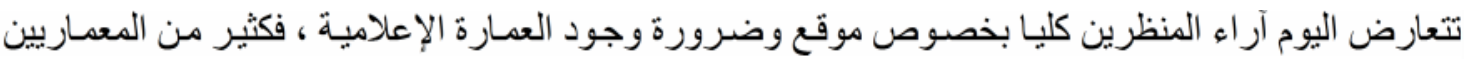

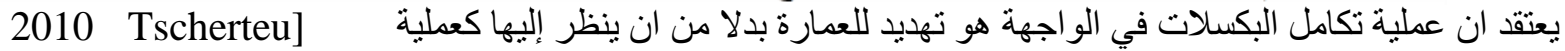

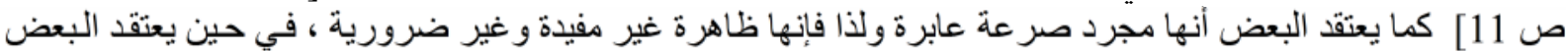
الآخر ان الو اجهات الإعلامية سوف تصبح في نهاية المطاف نوع من أنظمـة البنية التحتية الحديثة للمدن. Tovarovic

[203 2011

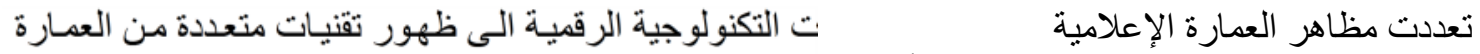

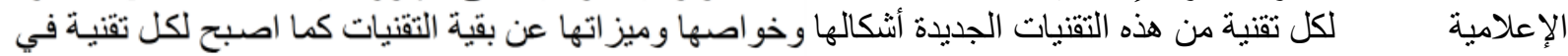
نفس الوقت سلبياتها ونقاط ضعفها في التطبيق.

\section{كما توسعت مجالات تطبيق العمارة الإعلامية}

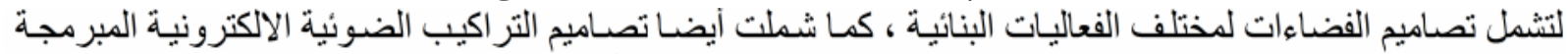

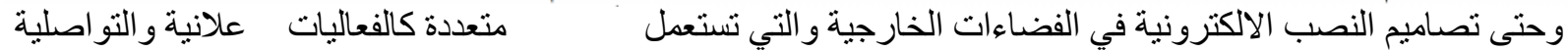

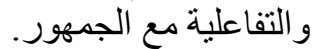

الإعلامية حديثة العهد ولم يمض عليها وقت طويل | تعدد تقنياتها وتوسع تطبيقاتها

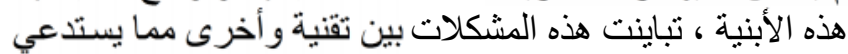
أظهرت استها وتأثنير ها وبيان الفروق بينها.

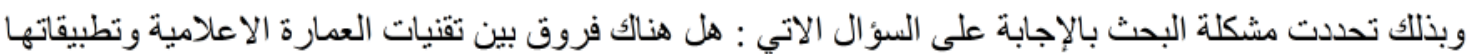

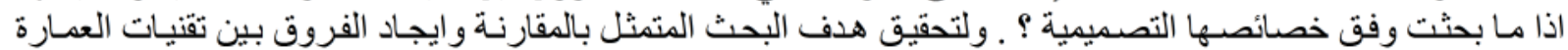

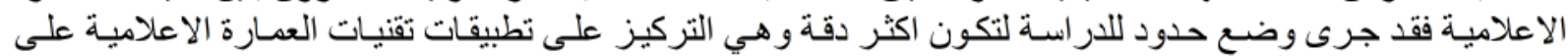

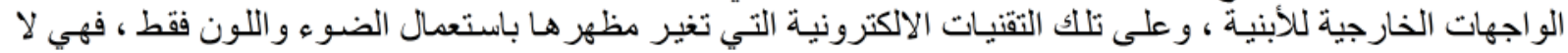

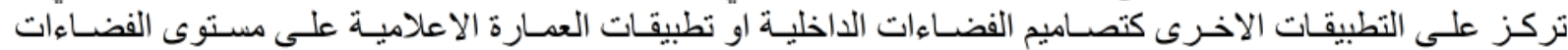

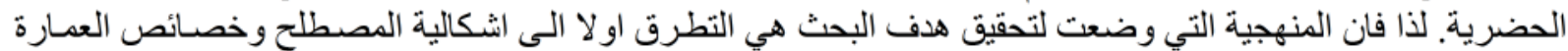

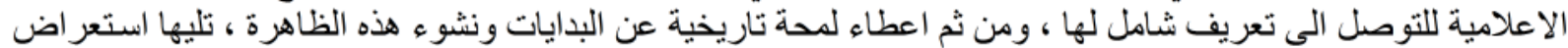

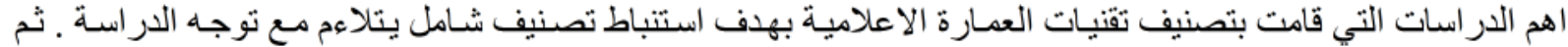

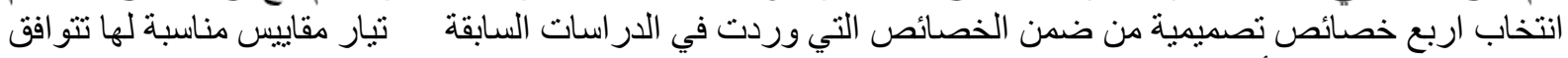

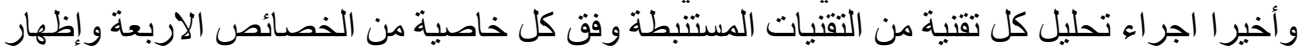

الفروق بينها من خلال الاستنتاجات التي توصل اليها البحث.

\section{1}

يمكن تعريف الواجهات الإعلامية بأنها تلك السطوح أو الأغلفة أو الأغشية التي تخاطب الجمهور العام من خـلال

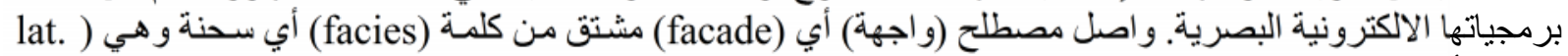
(Face 2011 Wachlowski] البشرية البرجة

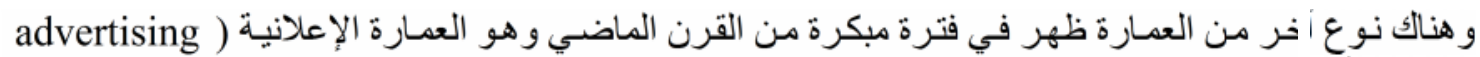

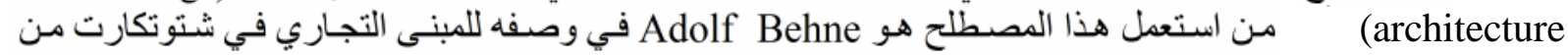




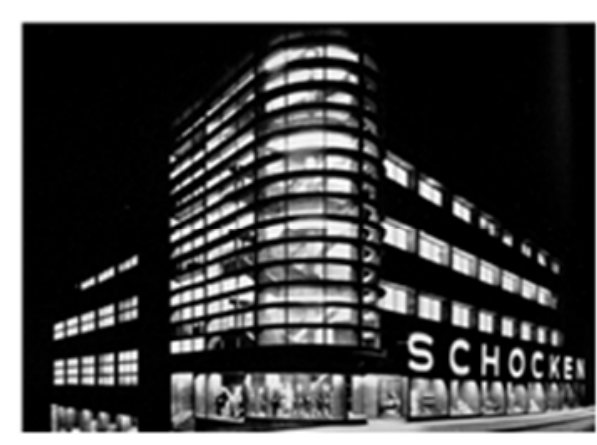

(1)

$\left[\begin{array}{lll}1097 & 2012 & \text { Moza }] \\ 1928\end{array}\right.$

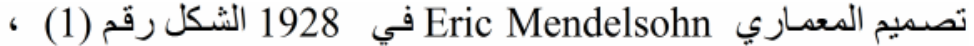

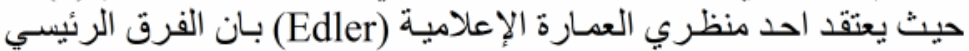

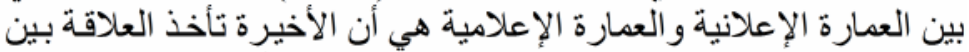

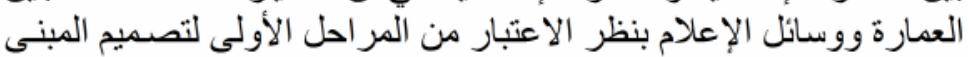

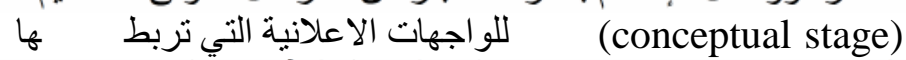

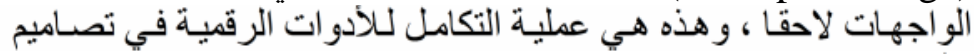
الأبنية مكانيا وهيكليا وبيئيا [ 2012 Moza

وبنفس المفهوم آثارت در اسـة (2010) Tscherteu) الموسومة

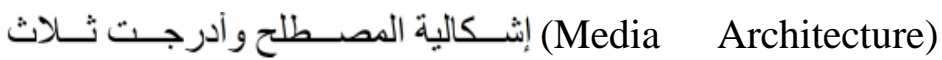
مصطلحات مختلفة منداولة ومرتبطة كثير ا ببعضها البهات اليو و هي :

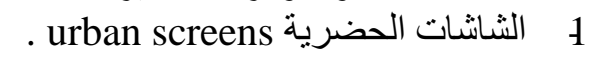
2 الواجهات الإعلامية الإنة 2 3edia architecture العمارة الإعلامية الاعلامية

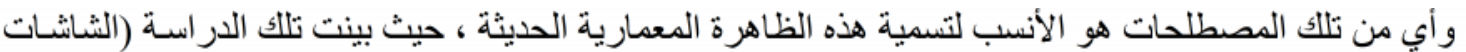

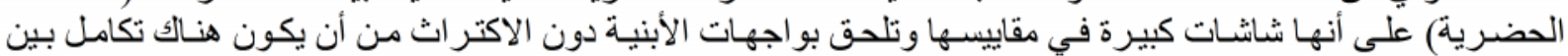

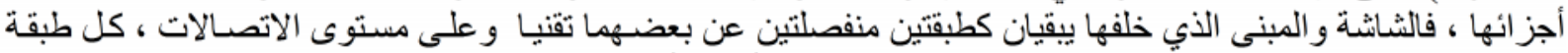

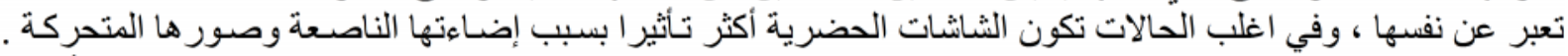

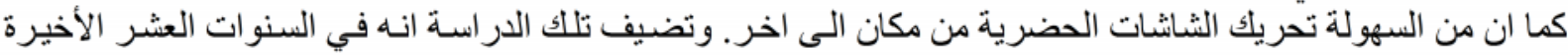

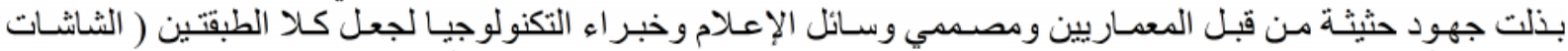
و المباني) أكثر قربا من بعضهما إن لم يكونا متكاملين في هيكل هجيني جديد يشار إليه بأنه (الو اجهة الإعلامية).

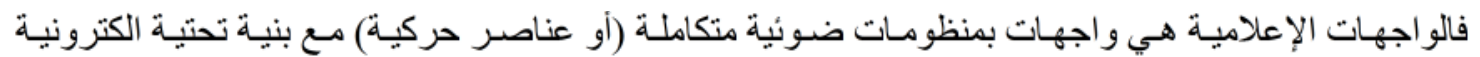

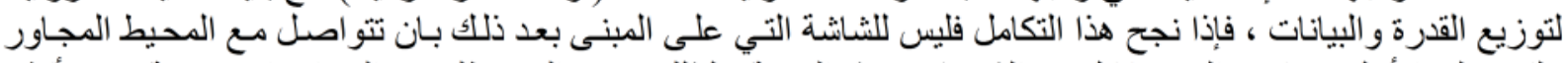

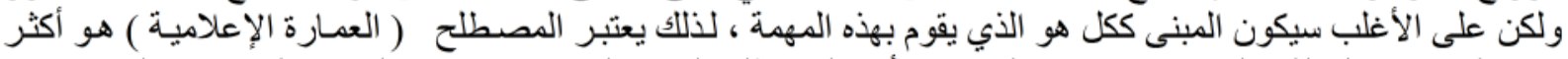

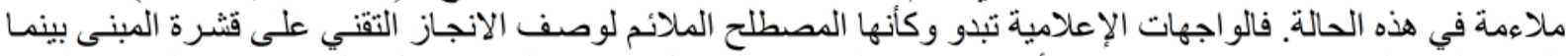

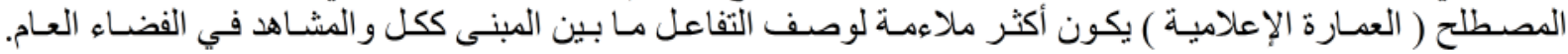

. [9 2010 Tscherteu]

وفصلت در اسـة آخرى بعنوان (Media Facades, History, Technology, Content) المصطلحات الثُلاث

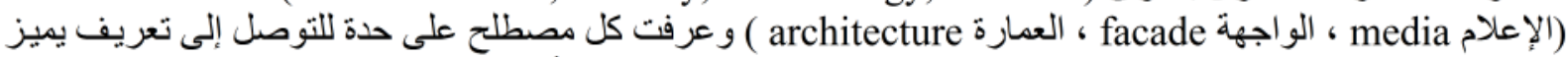

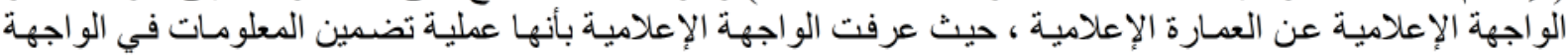

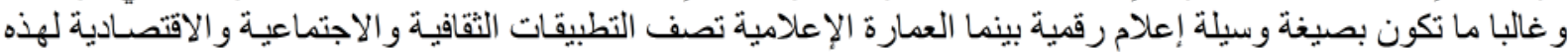

الواجهات في البيئة المباشرة [ Haeusler

[10 2010 Tscherteu]: وباختصار فان العمارة الإعلامية لهاو

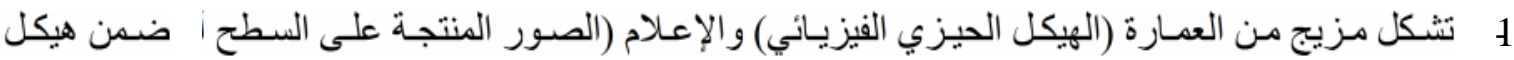
2

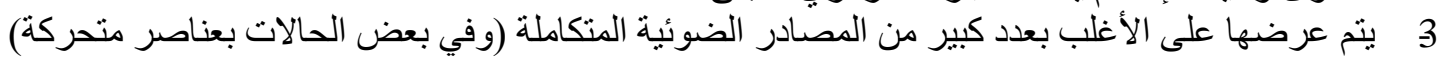
4 5 5 محتوى العرض في كثير من الحالات لا يكون تجريديا بل مقرو عا ومنظور ا ويخلق حوارا مابين المبنى و المشـاهد

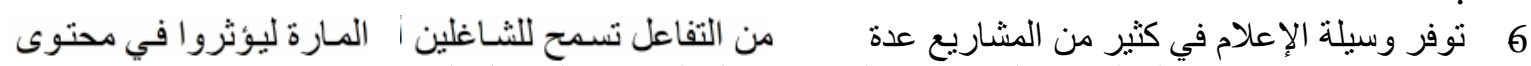

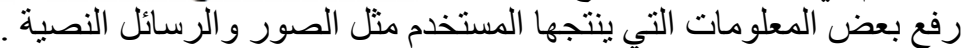

7 


$$
\text { تقدم يمكن تعريف الو اجهات الاعلامية بما يأتي : }
$$

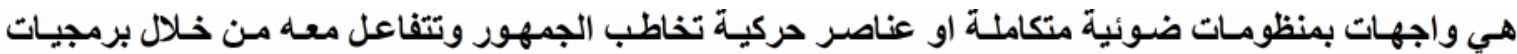

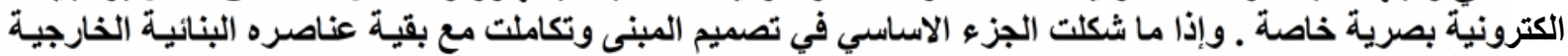

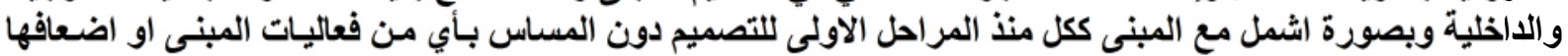

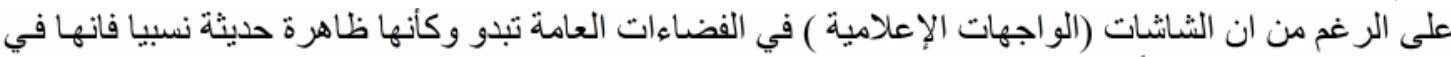
: 2 1

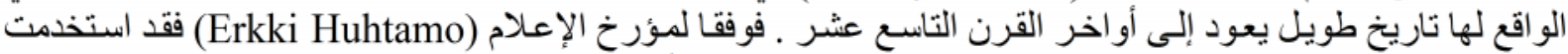

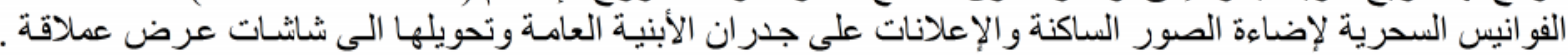

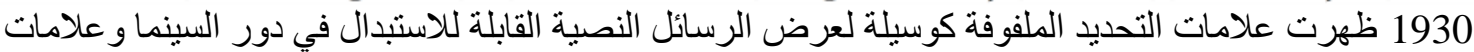

[82-31 2007 Huhtamo].

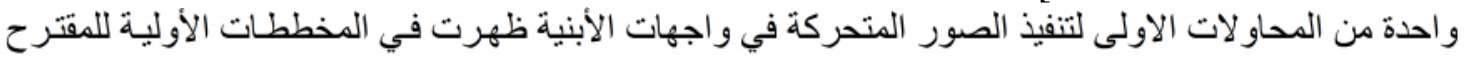

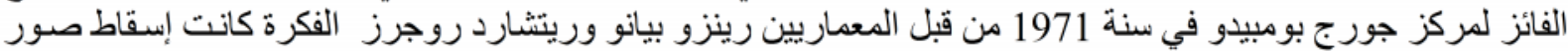

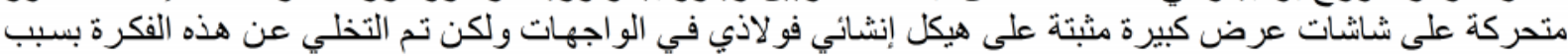

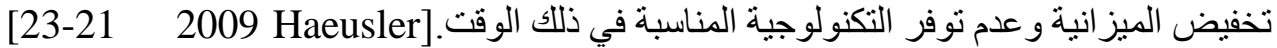

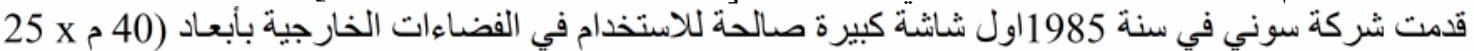

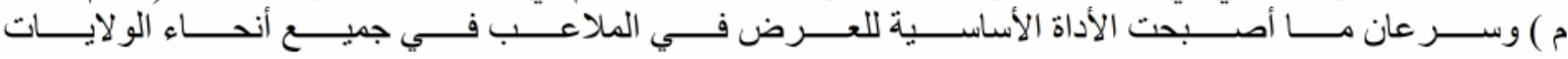
[en.wikipedia.org.wiki/jumbotorn].

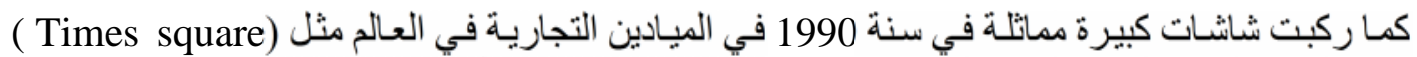

35 2009 Haeusler]. نيويورك وفي ميدان البيكاديللي في لندن و عدد من الفضاءات الحضرية التجارية الأخرى التين

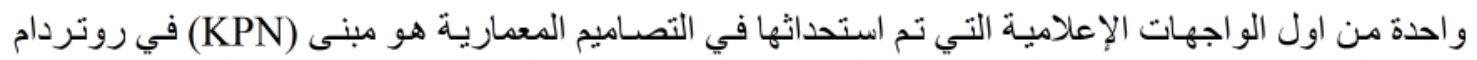

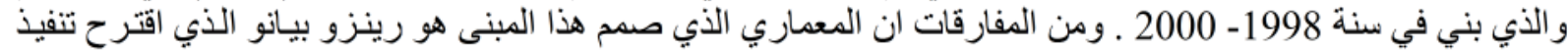

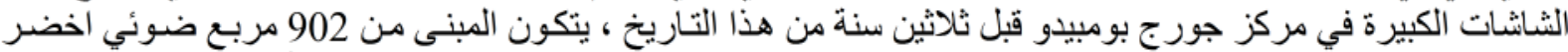

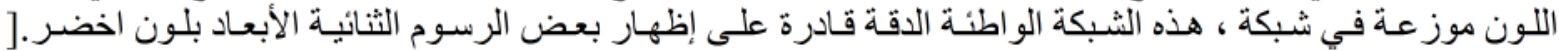

[www.rpbw.com/project/47/kpn

ي سبتمبر 2001 استأجرت مجمو عة صغيرة من المبرمجين مبنى إداري فارغ في في برلين و استخدموا مصابيح

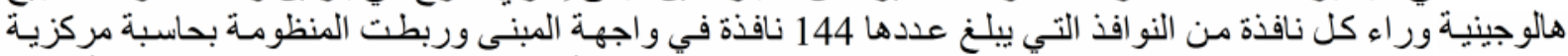

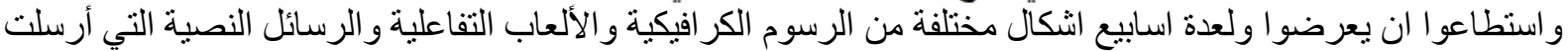

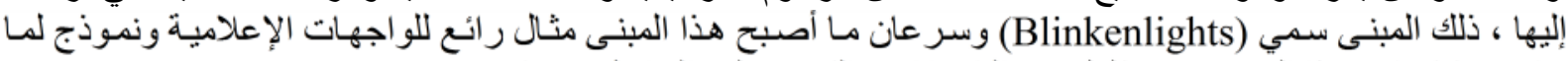
يمكن تحقيقه في هذا الصدد بعدد قليل من البكسـلات و القدرة على التفاعل مـع الثاشـات. blikenlights.net/project]

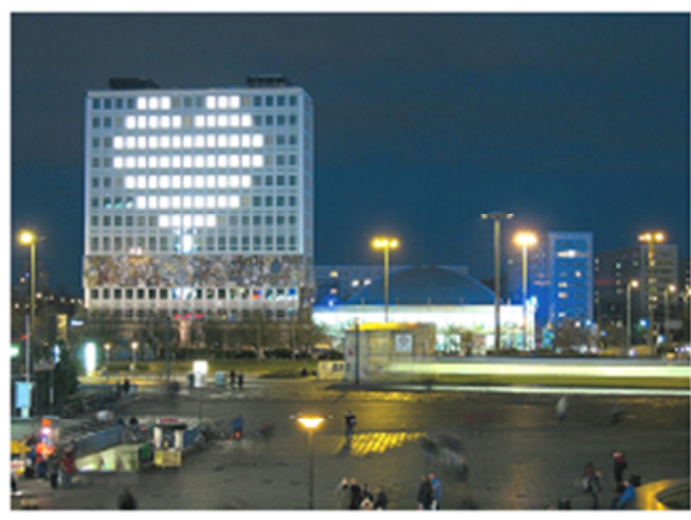

Blinkenlights

(3) [blikenlights.net/project]

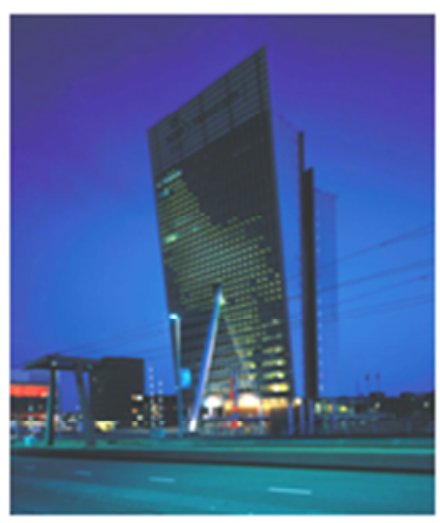

للمعماري رينزو بيانو KPN

(2)

[www.rpbw.com/project/47/kpn] 


\section{2}

صنفت العـارة أو الو اجهات الإعلاميـة مـن قبل العديد من البـاحثين ومن عدة نـواحي مختلفة ومن أهم هذه

الدر اسات التي تناولت هذا الموضوع الواجعات :

2

$$
\begin{aligned}
& \text { قسم هوسلر الواجهات الإعلامية أولا إلى قسمين رئيسيين: } \\
& 1 \\
& 2
\end{aligned}
$$

الو اجهات الميكانيكية تغير مظهر ها باستعمال القوى الميكانيكية أما الواجهات الالكترونية فتغير مظهر ها باستعمال الضوء و اللون ، وهي واسعة التطبيق في اغلب الأمثلة المعاصرة.

ثم فصد ”ل هذا التقسيم إلى أربعة مجاميع اعتمادا على كيفية عرض محتوى الإعلام على الواجهات ، هذه المجاميع هي :

$$
\begin{aligned}
& 1 \\
& 2 \\
& 3 \\
& 4
\end{aligned}
$$

المجاميع الثلاثة الأخيرة تسمح بتنوع أكثر اعنمادا على كيفية عمل تكنولوجيا كل منها وبذلك آصبح التصنيف يقسم إلى ست

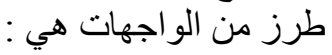

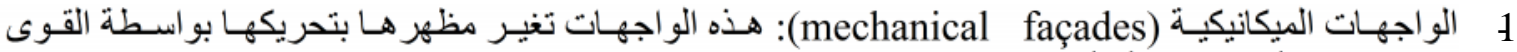

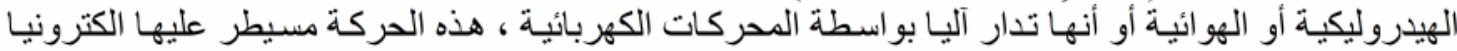

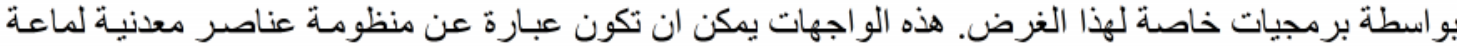

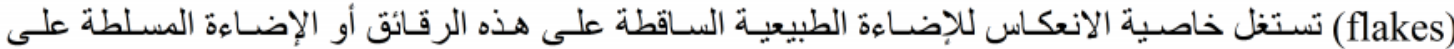

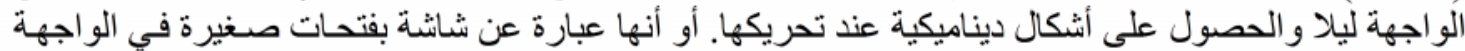
ينم السيطرة على غلقها وفتحها الكترونيا لإظهار صور ديناميكية مختلفة.Haeusler،

2 و واجهات الإسقاط الأمامي (front projection façades): إسقاط محتوى المادة الإعلامية مباشرة على الواجهة

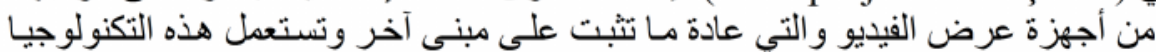

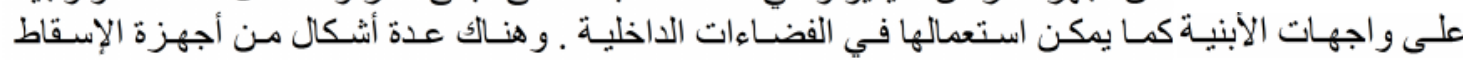

58 و التي تختلف في مو اصفاتها تقنيا. [projectors)

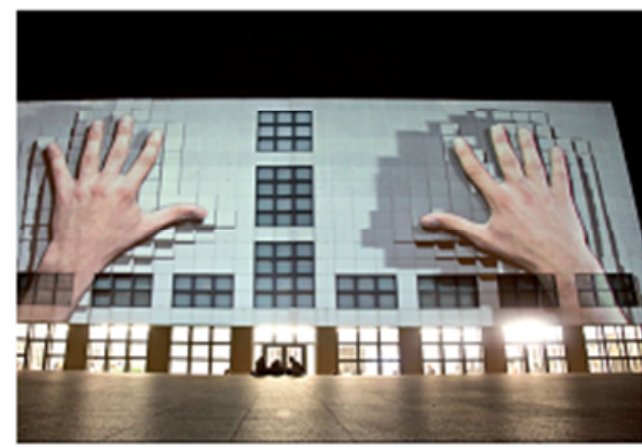

(5) معرض هامبورك للفن المعاصر و اجهات الإسقاط الأمامي [160 2010 Kronhagle]

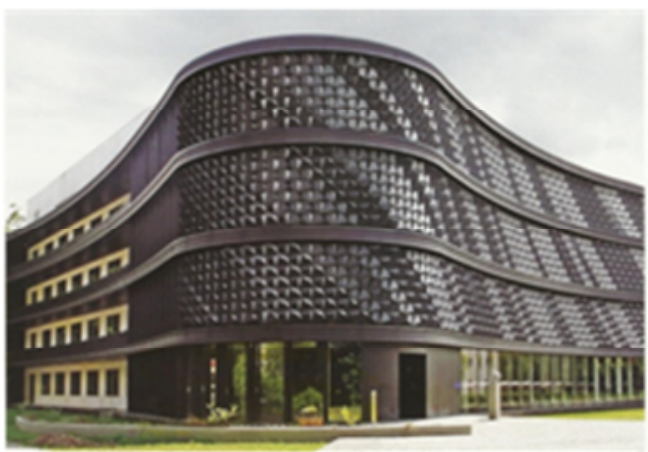

(4) الو اجهات الميكانيكية (لاتز ال فكرة) [50 2009 Haeusler] 
3 و واجهات الإسقاط الخلفي (back projection façades): إسقاط محتوى المـادة الإعلاميـة من داخل المبنى أي

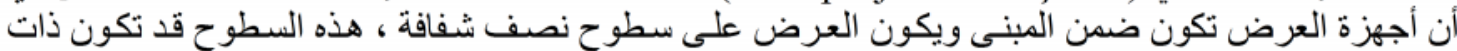

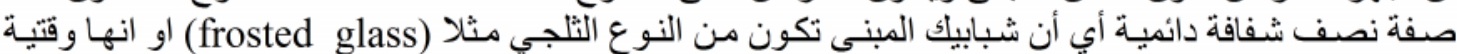

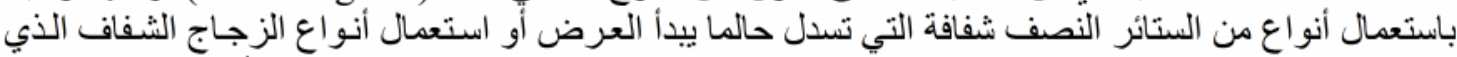

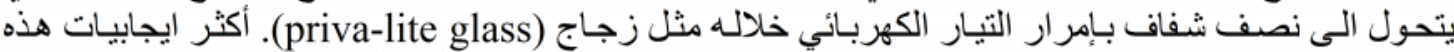

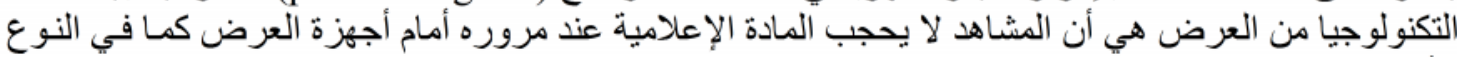
(6 ) 2009 Haeusler]

4 و واجهات العرض (display façades): تقديم المحتوى من خـال شاشـات عرض كبيرة جدا يمكن الحصول

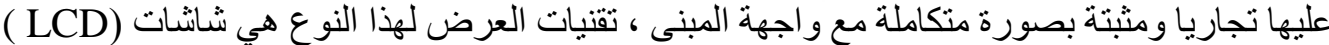

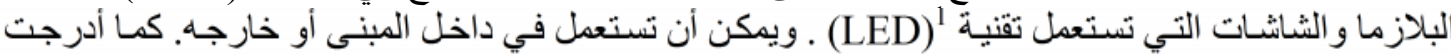

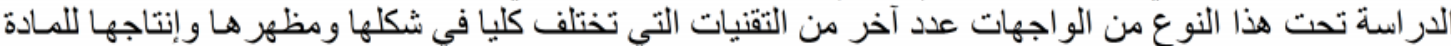

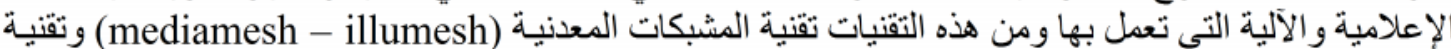

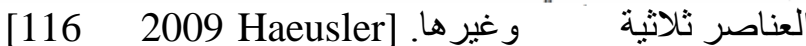

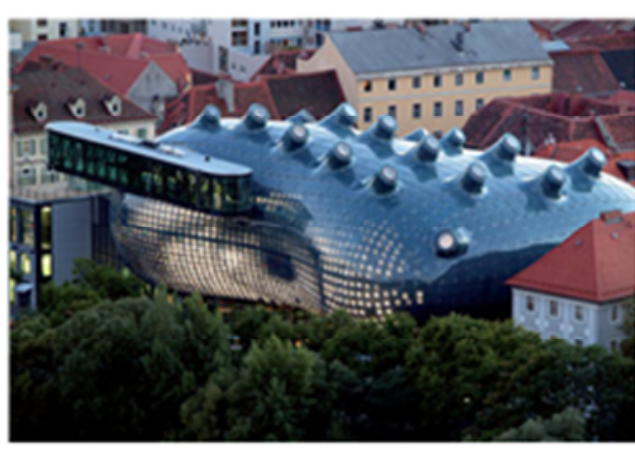

BIX (7)

(الو اجهات المضاءة)

[101 2009 Haeusler]

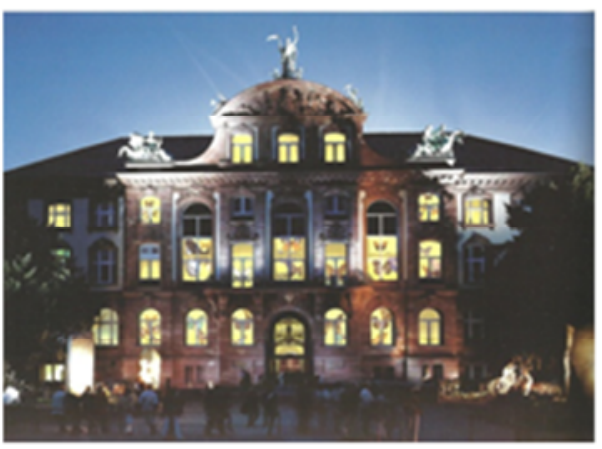

[86 2009 Haeusler]

5 و واجهات الرسوم المتحركة النقطية بواسطة الثبابيك (window raster animation technology):

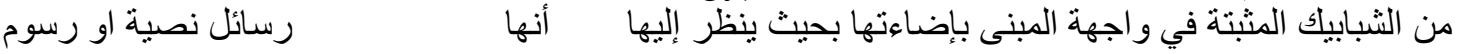

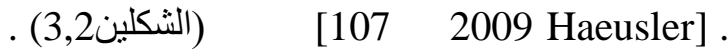
الو اجهات المضاءة (illuminated façades): تثبيت تر اكيب المتغيرة الثدة (dimmable) العادية او النيون في سطوح الو اجهات بصورة متكاملة للحصول على رسوم متحركة باللونين الأبيض

. $)$ (7) 2009 Haeusler $]$

(Medienfassaden 2008) (Gunner Schmidt ) دراسة شميدت

صنفت الدر اسة الو اجهات الإعلامية إلى أربعة طرز اعتمادا على كيفية تفاعل هذه الو اجهات في الفضاءات الحضرية ، لذا

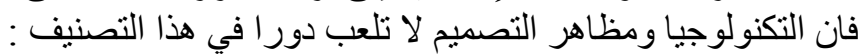
[www.medienaesthetik.de/medien/fassade.html]

1

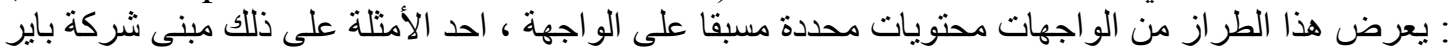

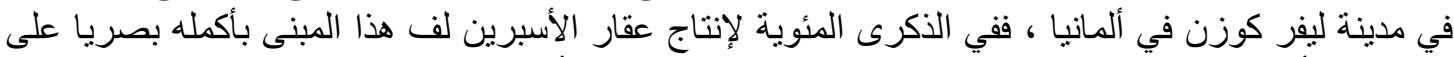

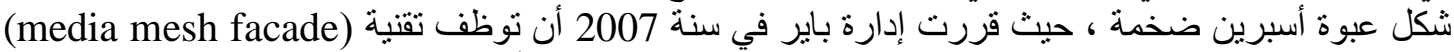

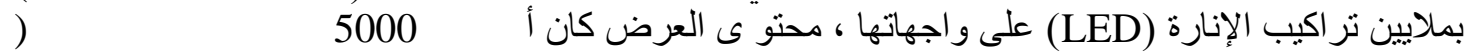


المبان (Interactive Mode)

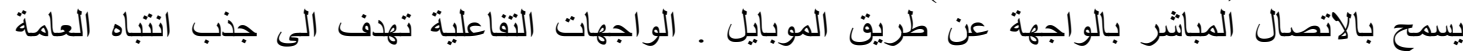

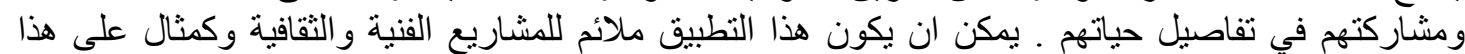

\section{(3) (Blinkenlights)}

3 الطراز البيئي (Environment Mode / Reactive Mode): يفترض هذا الطراز بان الواجهة الإعلامية

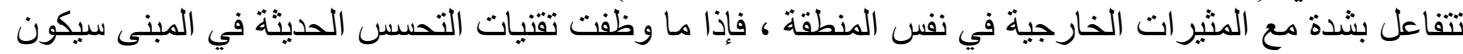

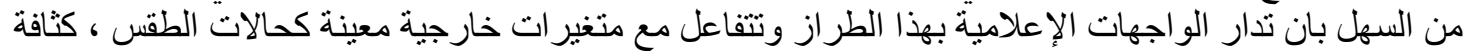

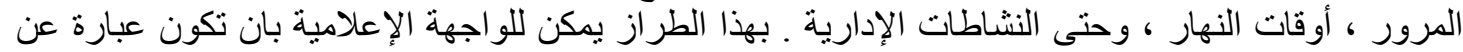

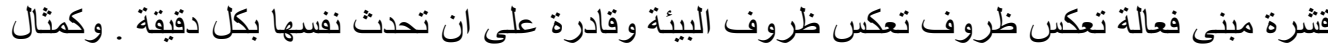

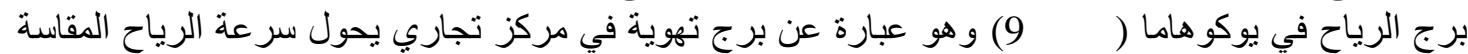

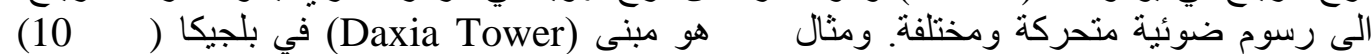

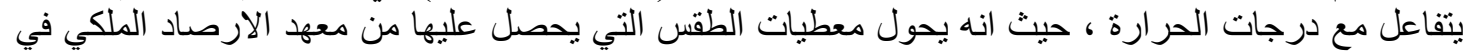

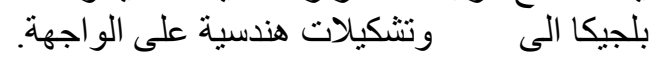

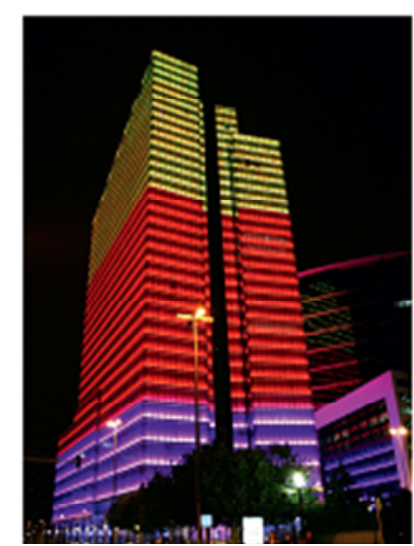

Daxia
(10)

بلجيكا

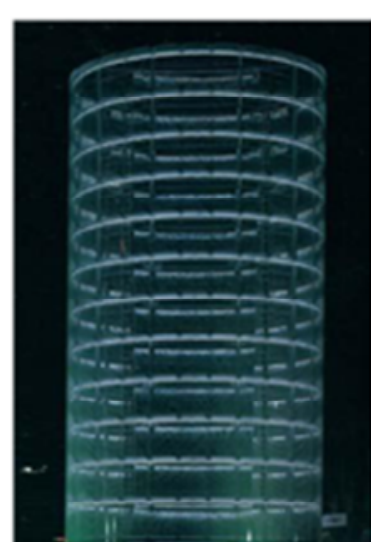

(9)

الرياح في يوكو هاما

[37 2011 Wachlowski]

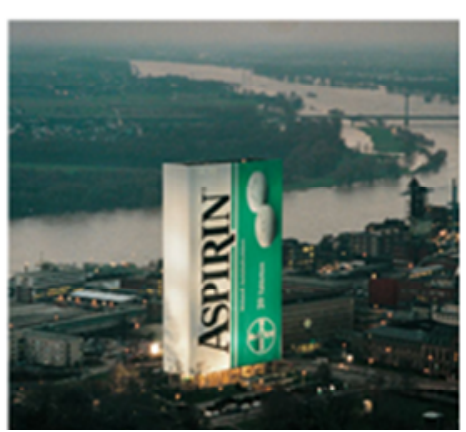

(8) مبنى شركة باير

[ww.medienaesthetik.de/medie [n/fassade.html

\section{[135 2010 Kronhagle]}

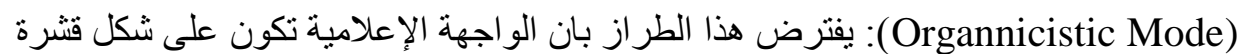

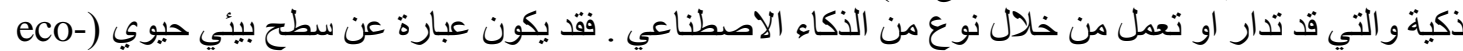

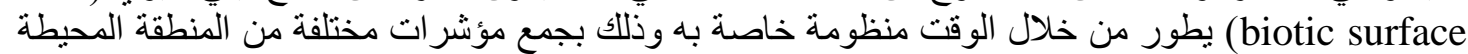

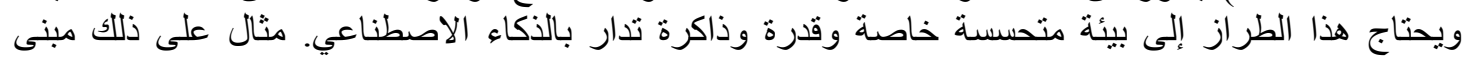

$$
\text { ( ) (Bix) }
$$

\section{Interactive Media Facades in the Urban Context ,2011 ( Wachlowski)}

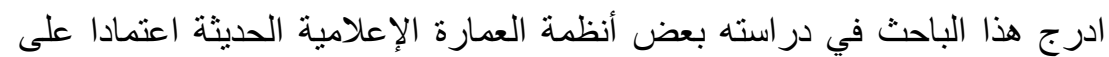

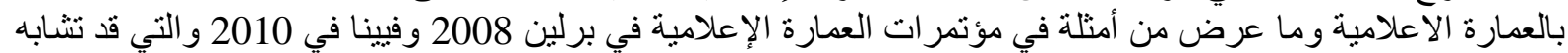
ما ورد في در اسة هوسلر 2009 هذه النظم (كما سماها) : 2011 Wachlowski

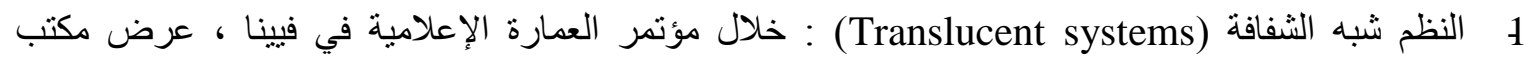

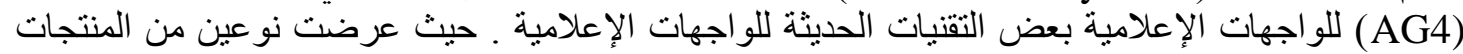

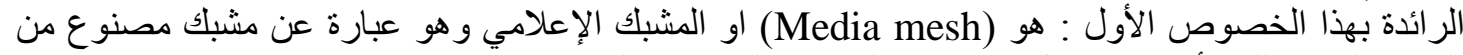
(LED) الفو لاذ المقاوم للصدأ منسق بشكل متو ازي و والقضب التبان المحتوية على تر اكيب الانا

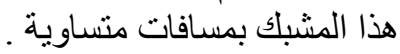




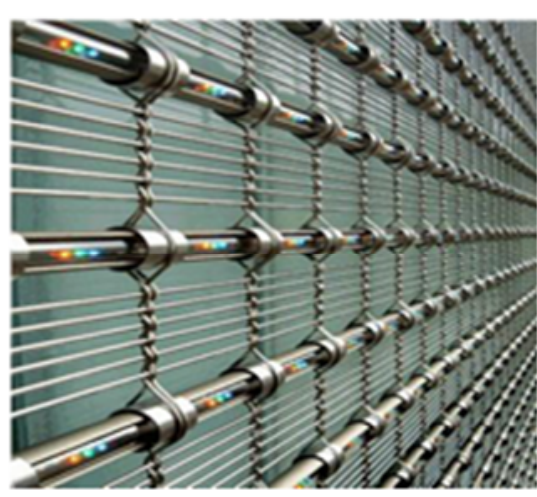

(11) - (11) النظم شبه الثظفافة

[mediamesh] www.Gkdmedia mesh.com

هذا المنتج يمكن ان بركب ويزال بسهولة على الواجهات المنفذة .

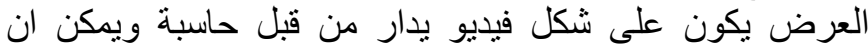

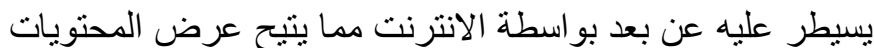

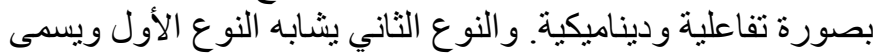

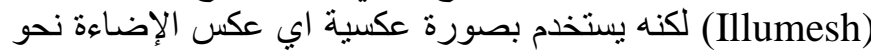

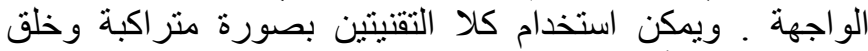

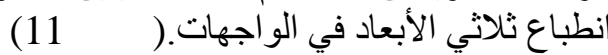

النظم غير الثفافة (Opaque systems): المبدأ الذي تقوم عليه

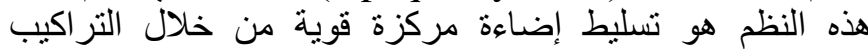

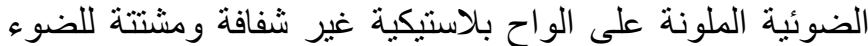

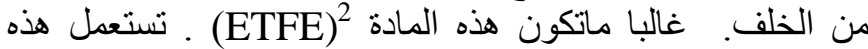

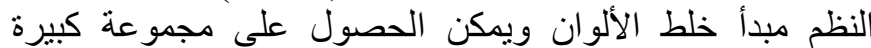

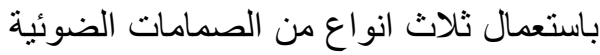

\section{$(12)$}

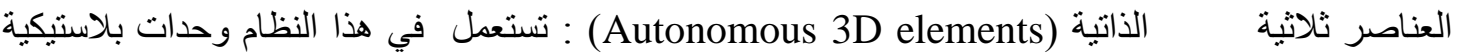

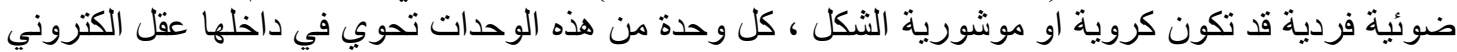

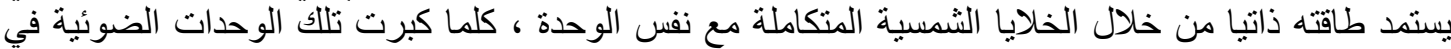

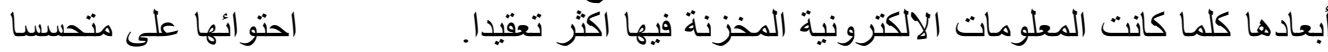

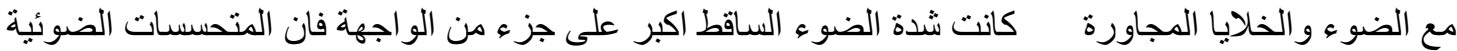

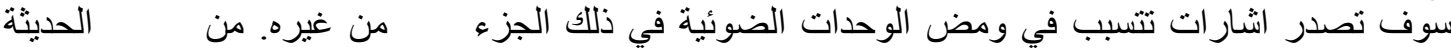
للعناصر ثلاثية

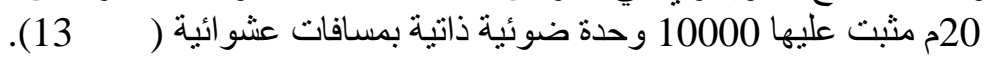

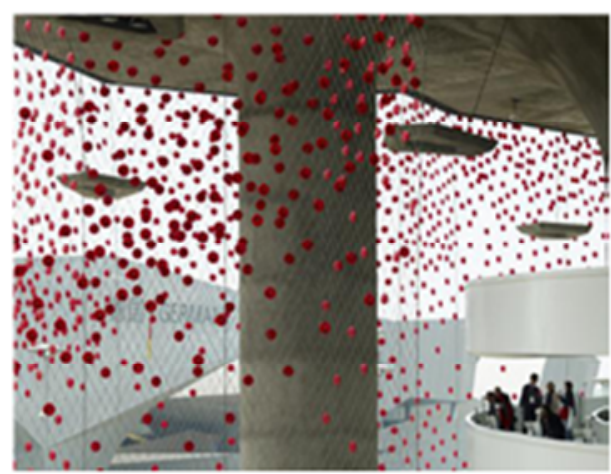

ثلاثية الابعاد (و اجهة الجناح السويسري في معرض شنكهاي 2011 الابعاد

[43 2011 Wachlowski]

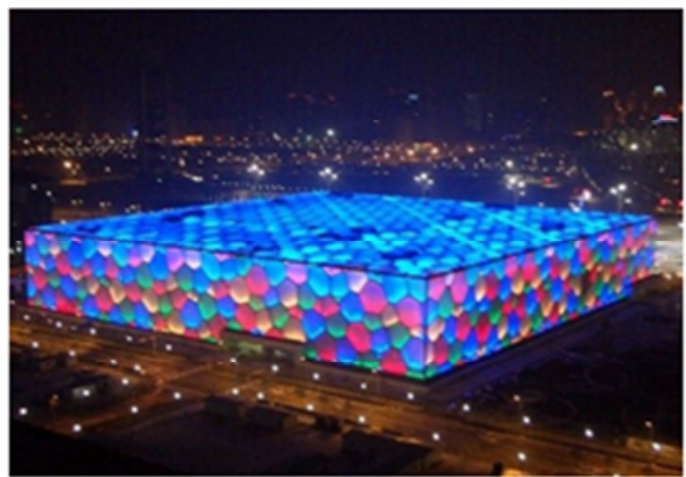

(12) النظم غير الثفافة (المكعب المائي في الصين غالنين

[www.seeingtheworld39.blogspot.com

و هناك عدد من التصانيف التي وردت في دراسات اخرى والتي هي إما تقترب كثير ا من التصانيف المذكورة أو أنها

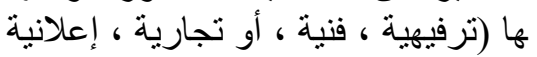

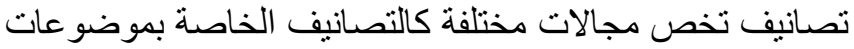
) أو أنها تخص تكنولوجيا الاتصالات التي تعتمد عليها وسيلة الإعلام في الواجهات الإعلامية وهي ليست مجال فئ بحتنا. 
(1)

وبعد إدراج هذه التصانيف للواجهات الإعلامية

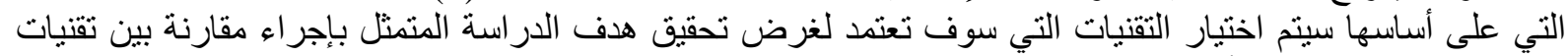
الو أجهات الإعلامية وفقا لأسس تصميمية معينة :

1

2

3

(1) يوضح التصنيفات الرئيسية للعمارة الاعلامية (الباحث)

\begin{tabular}{|c|c|c|c|}
\hline التقنيات و الطرز و النظم لكل تصنيف & & التصنيفات الرئيسية للعمارة الاعلامية & \\
\hline 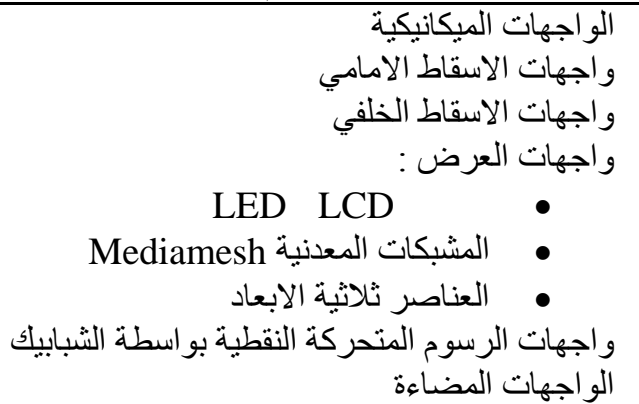 & $\begin{array}{l}1 \\
2 \\
3 \\
4\end{array}$ & 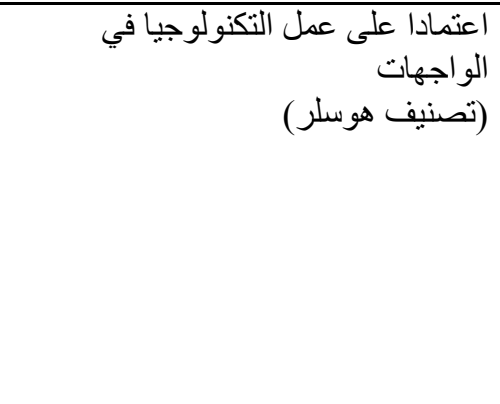 & 1 \\
\hline الطر از البيئي البي & $\begin{array}{l}1 \\
2 \\
3 \\
4 \\
\end{array}$ & الفضاءات الحضى كيفية تفاعل الو اجهات فية & 2 \\
\hline 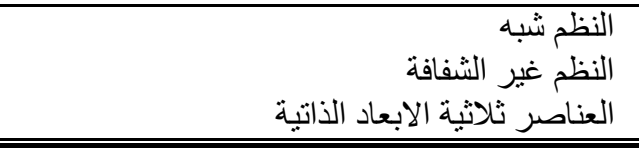 & $\begin{array}{l}1 \\
2 \\
3 \\
\end{array}$ & بالعمارة الاعلامية واجكي) & 3 \\
\hline
\end{tabular}

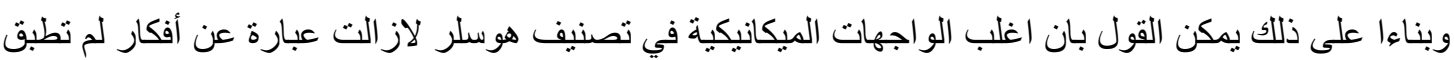

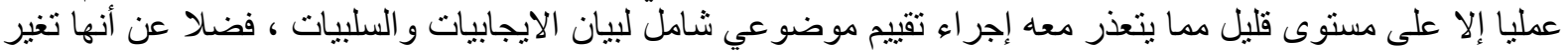

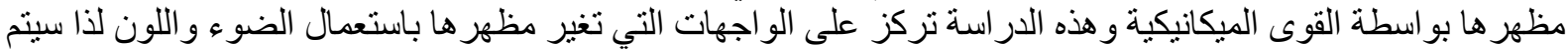

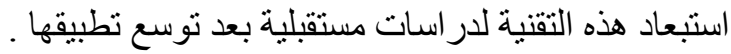

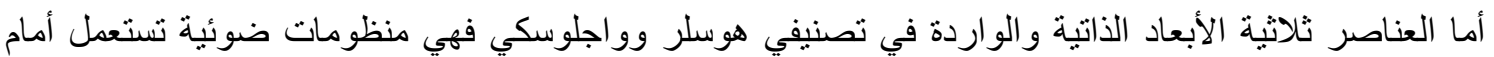

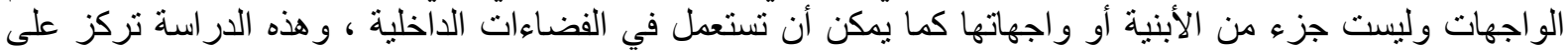

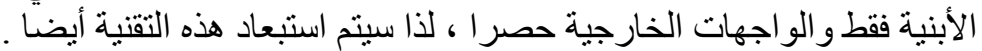

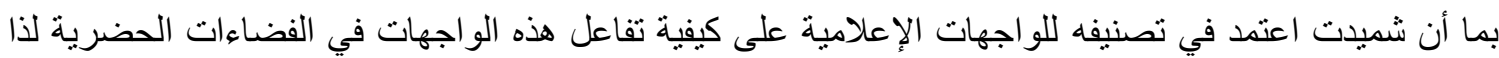

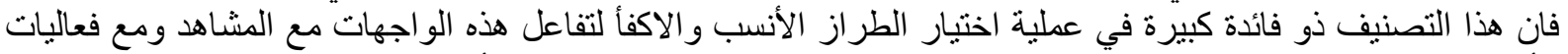

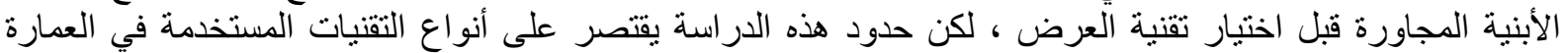

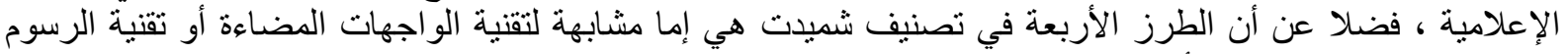

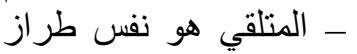

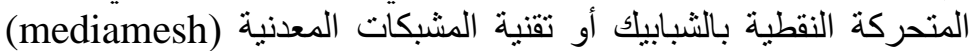
الواجهات شبه الثفافة (mediamesh) اما الطر ازين التفاعلي و البيئي فهما نفس تقنية الرسوم المتحركة النقطية بالثبابيك و الطر از العضوي هو نفس الواجهات المضاءة في تصنيف هوسلر.

وفي نفس الوقت فان واجهات الإسقاط الأمامي و الخلفي تستعملان نفس تقنية إظهار وسيلة الإعلام و الفرق بينهما

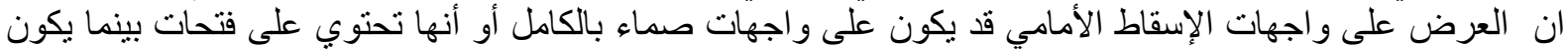

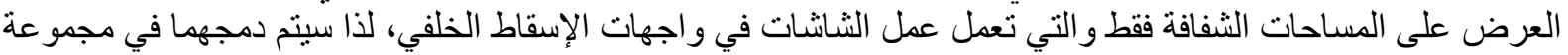


و احدة . كما أن واجهات الرسوم المتحركة النقية بالثبابيك والواجهات المضاءة تنشابهان إلى حد كبير لذا سيتم دمجها أيضا في مجمو عة و احدة .

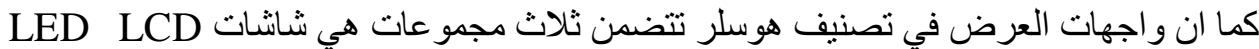

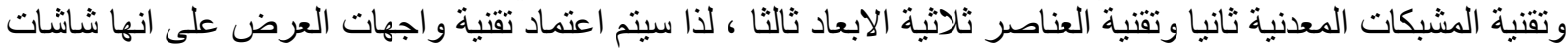
LCD LED

$$
\text { (2) يوضح كيفية استنباط التقنيات الرئيسية لإغر اض البحث (الباحث) }
$$

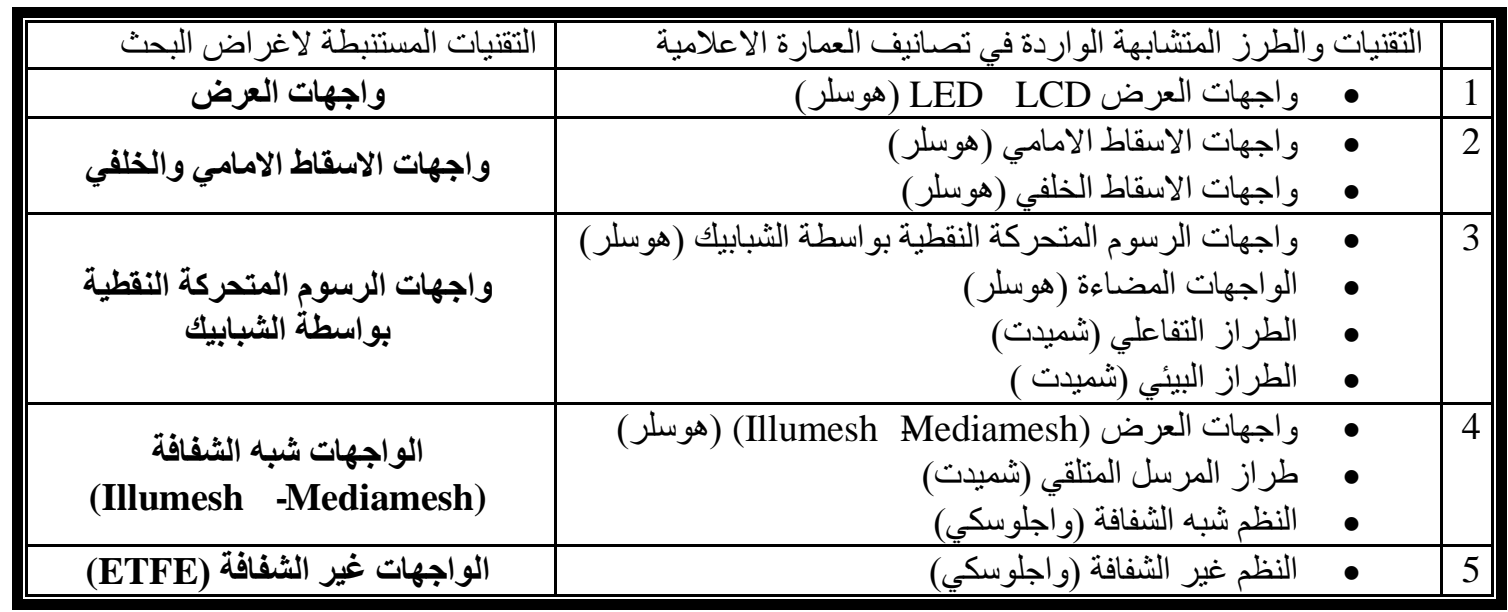

ونتيجة لذلك يمكن استتباط خمس تقنيات أساسية من هذه التصانيف :

$$
1
$$

2

3 4 الو اجهات شبه الثفافة (mediamesh - illumesh)

5 5

\section{3}

بعد ان توسعت مجالات تطبيق العمارة الاعلامية وظهرت تقنيات متعددة في اشكالها وخو اصها و التي رافقها

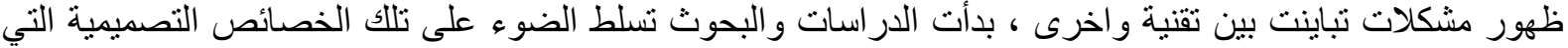
يمكن ان تتأثر نتيجة هذا التطبيق وبالتالي تؤدي الى اضعاف الفعاليات الاساسية للمبنى ـ ومن هذه الدراسات دراسة

(Media façade: fundamental terms and concepts , 2008) (Tscherteu)

(Moza)

(Specific problems of media façade design, 2011)

(Tovarovic) .اوردت هذه الدراسات عدد من الخصائص. (From advertising architecture to media façade, 2012)

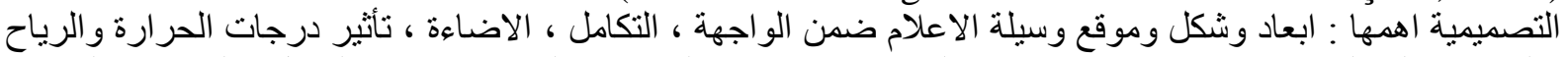

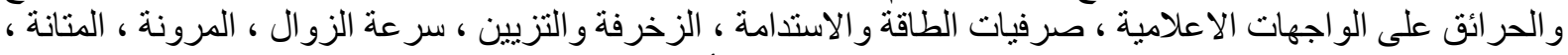

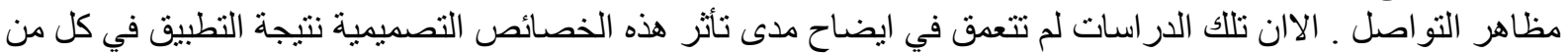

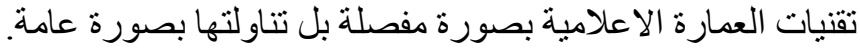

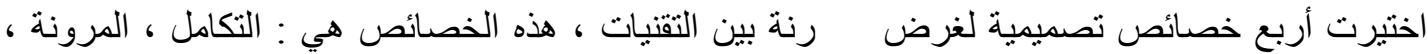
لر احة البصرية ، شكل الو اجهة الاعلامية. كون أكثر التحديات و المشاكل التي تواجه هذا النوع من العمارة والتي وردت في الدر اسات السابقة يتعلق بهذه الخصائص. 
ونتيجة لدر اسة أولية قام بها الباحث أيضا حول الموضوع تبين أن هذه الخصائص هي التي أظهرت أكثر من غير ها طبيعة

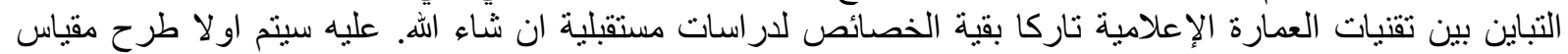

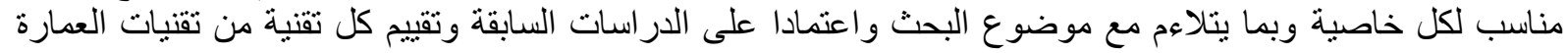

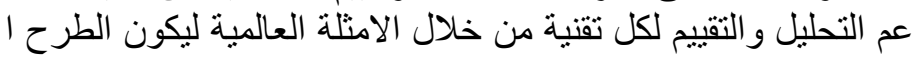

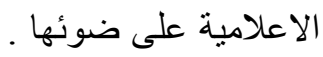
دقة وشمولية.

:

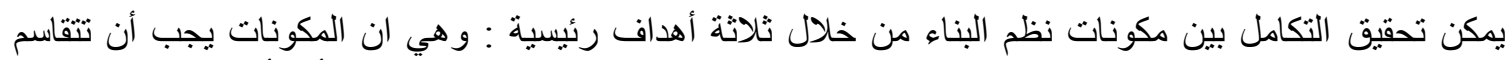

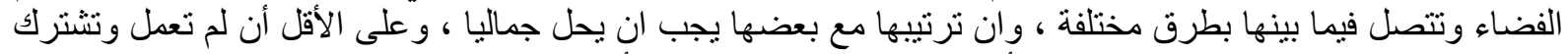

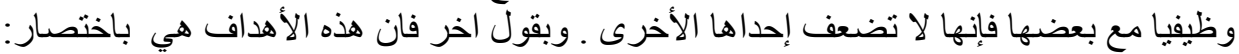

$$
\begin{aligned}
& \text { 1 } \\
& \text {. Visual integration } \\
& \text { [4 } 2003 \text { Bachman] Performance integration } \\
& \mathbf{1}
\end{aligned}
$$

يتكون أي مبنى من مجمو عة نظم بنائية تحقق الشكل الفيزياوي و الوظيفي للمبنى ، من هذه النظم يمكن تحديد أربعة (interior)

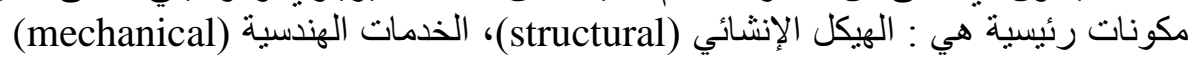
(envelope) الأربعة الذي لا يجعل منها مكونات مستقلة الواحدة عن الأخرى 1986 Rush

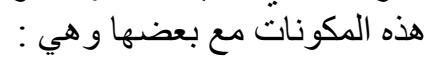

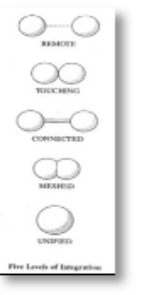

$\begin{array}{cl}\text { remote } & 1 \\ \text { touching } & 2 \\ \text { connected } & 3 \\ \text { meshed } & 4 \\ \text { Rush unified } & 5\end{array}$

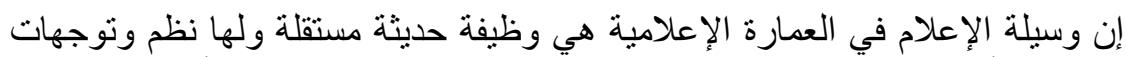

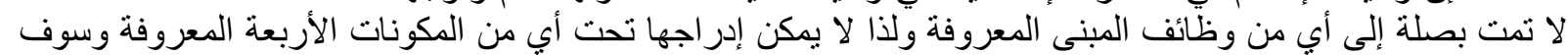

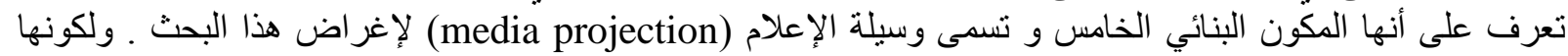

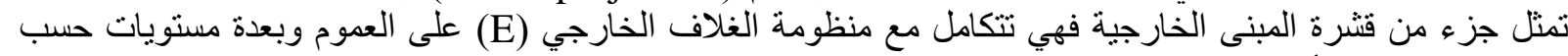
نوع وتقنية وسيلة الأعلام.

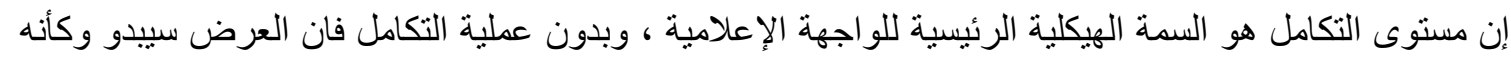

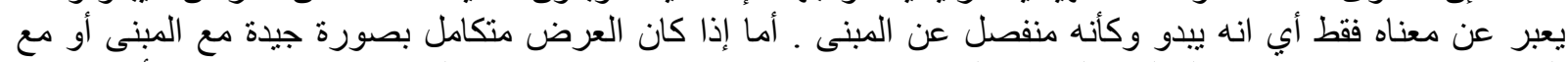

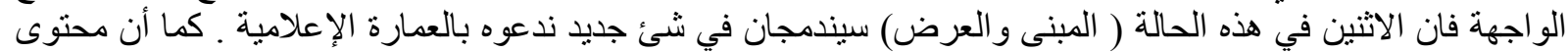

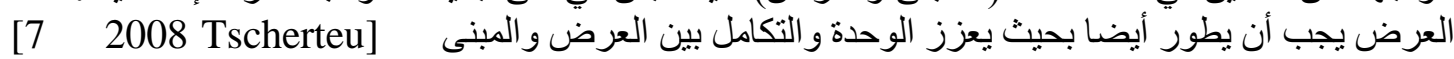
عندما يتعلق الأمر بمستوى التكامل بين الواجهة الإعلامية والمكونات البنائية الأخرى فسوف تظهر هناك حالتين رئيسيتين :

$$
\text { : : إضافة لاحقة لعناصر وسيلة الإعلام إلى هيكل أو مبنى مصمم مسبقا. }
$$

الثانية : تكون فيها عملية تصميم و إنشاء الو اجهة الإعلامية و الهيكل تسير ان بصورة منو ازية كعمل معماري متكامل. ان عملية التكامل بين الهيكل ووسيلة الإعلام يمكن أن تتحقق خلال عملية التصميم والإنشاء ولكن يمكن أيضا أن إن إناء تتحقق بعد عملية إنشاء المبنى أو الفعالية [ 2011 Tovarovic و وعلى هذا الأساس يمكن تقييم كل تقنية من تقنيات الواجهات الإعلامية ومستوى تكاملها مع وسيلة الإعلام لبيان

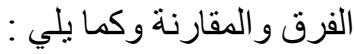




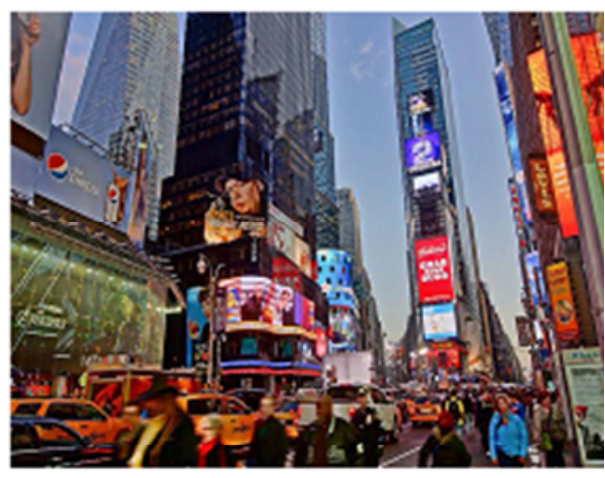

Times square التكل رقم (14) ابنية في نبويورك ابنك

[www.wikimediacommons.com]

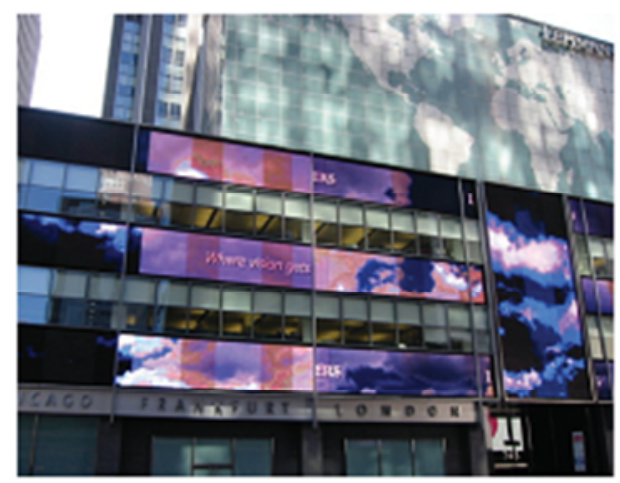

Lemans brother

$$
\text { في نيويورك }
$$

[www.webdesignerdepot.com]
1

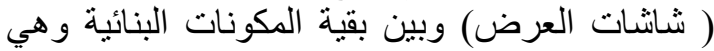

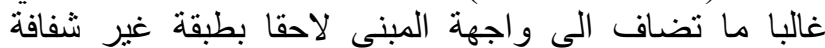

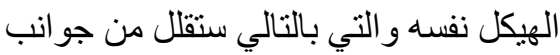

والوظيفة square

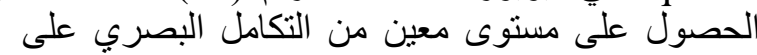

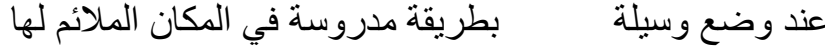
في الواجهة كاستغلال المساحات الصماء

(Galeria store)

Lemans

شبابيك او الستائر في

brother

و واجهات الإسقاط الأمامي و الخلفي : لا يوجد ايضا اي نوع من التكامل بين وسيلة وبقية المكونات البنائية

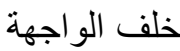

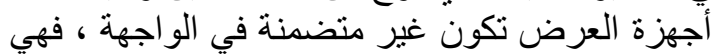

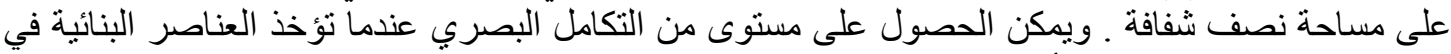

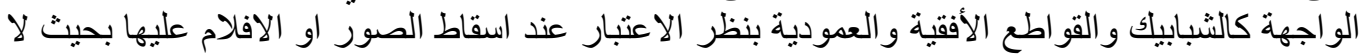

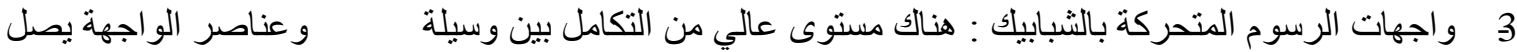

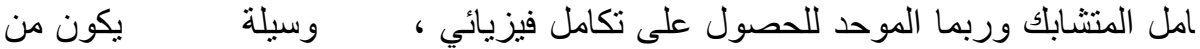

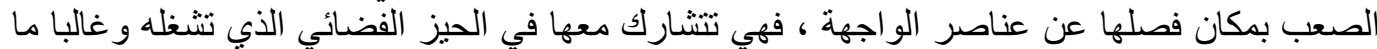

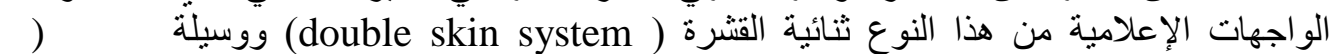
التر اكيب الضوئية من نوع LED) في الحيز الفضائي بين القشرتين

4 الواجهات شبه الثفافة : ان وضع المشبكات المعدنية الحاوية على التر اكيب الضوئية (LED) امام الواجهات

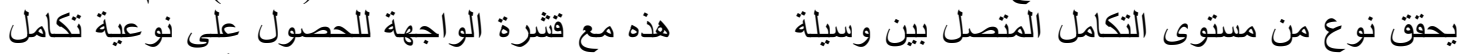

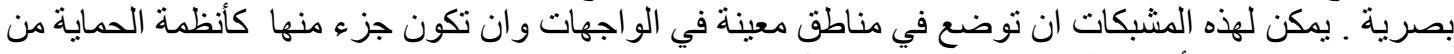
.(17)

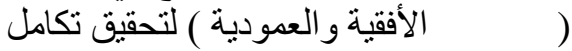




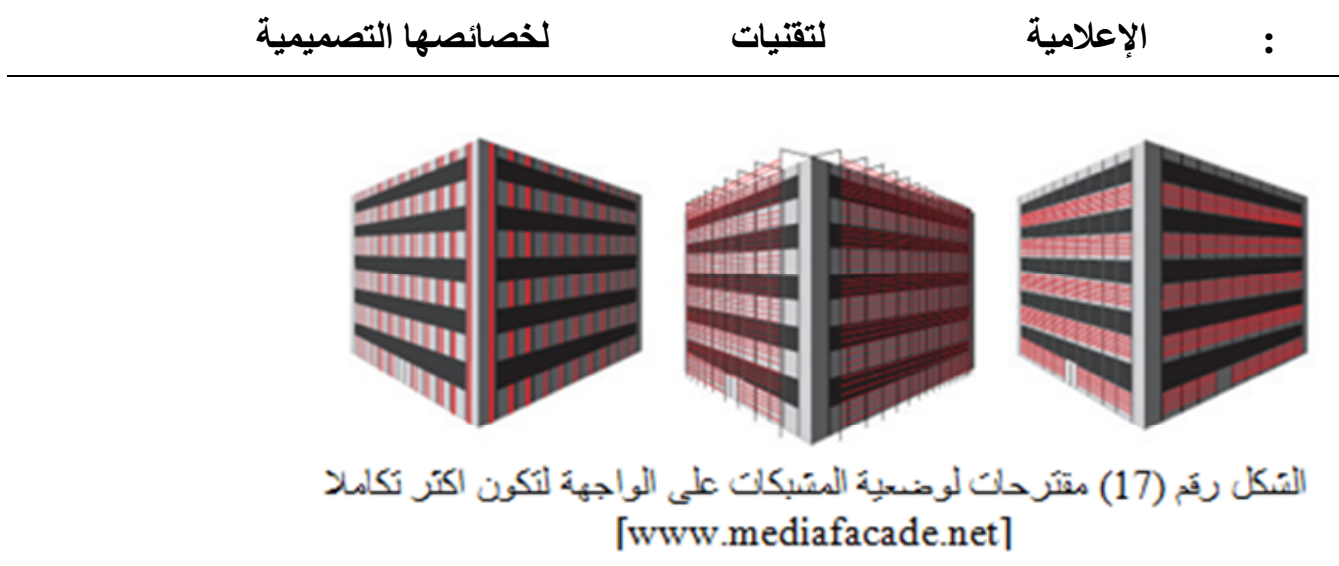

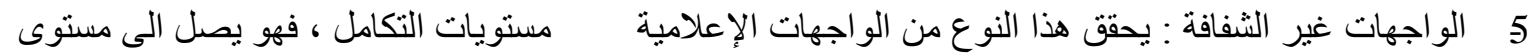

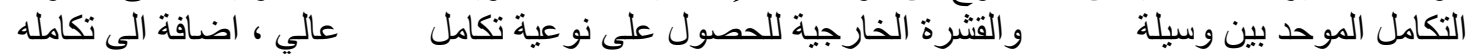

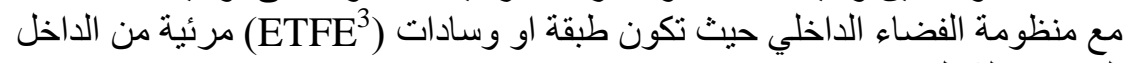
الصين ، الثكل رقم (12) . (12)

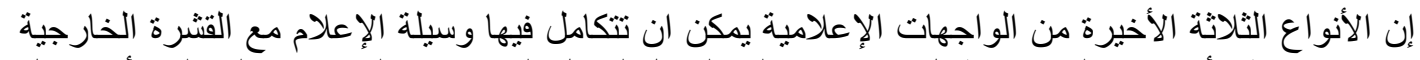

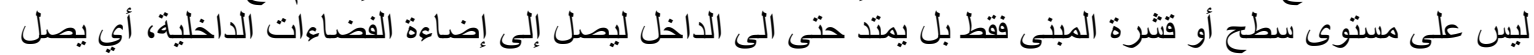

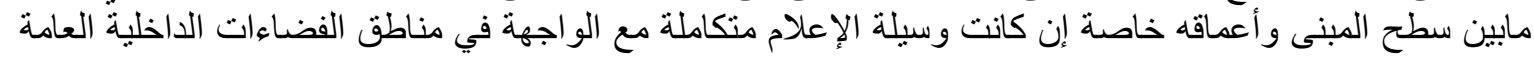

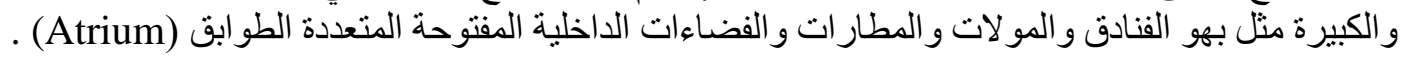

:

عرفت المرونة من قبل العديد من الباحثين وشرحت معانيها بصيغ مختلفة ـ فقد عرفت

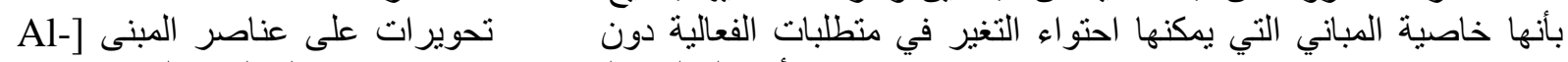

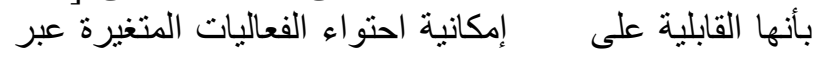
2016 Fawcett] تحوير ات ، لهذا فان كمية المرونة في المباني لا يمكن يحدد دون معرفة كمية التغير في الفعالية وكمية التغير الحاصل لملائمة هذه التغيرات [114 1985 Al-Nijaidi

$$
\text { الإعلامية لها مظهرين : }
$$

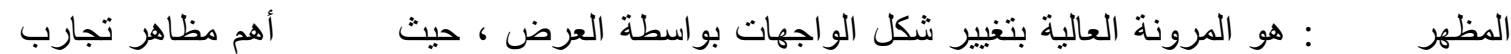

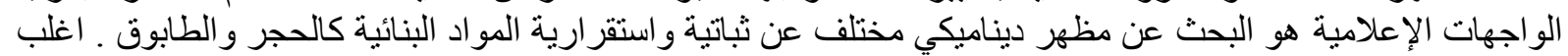

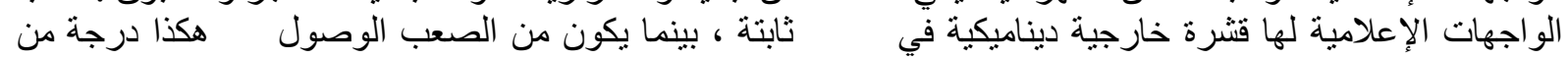

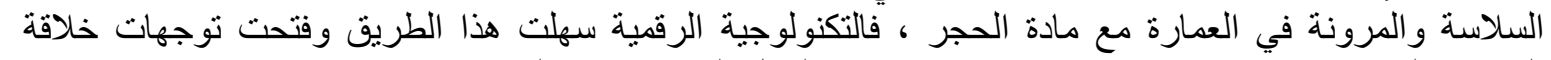

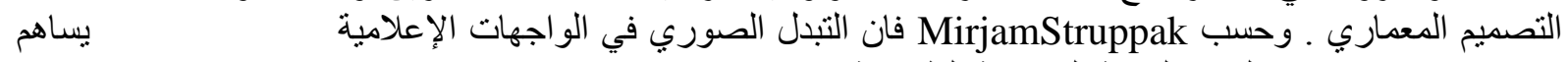
تغيير خو اص المواد البنائية الفيزيائية الظاهرية ( dematerialization ) 2012 Moza]

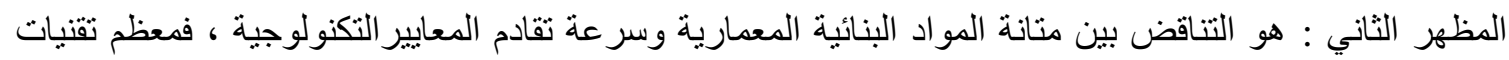

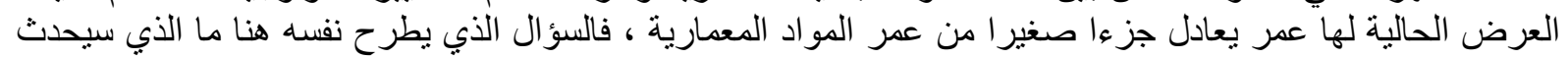

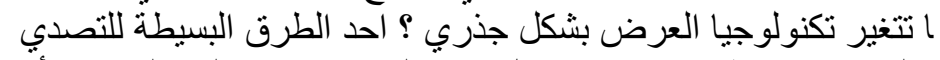

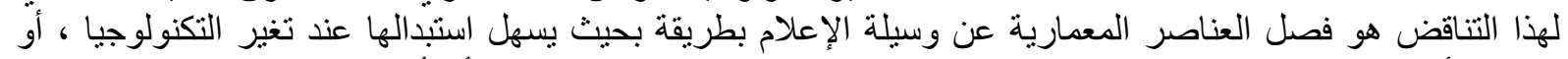

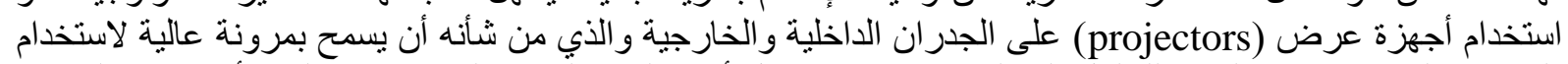

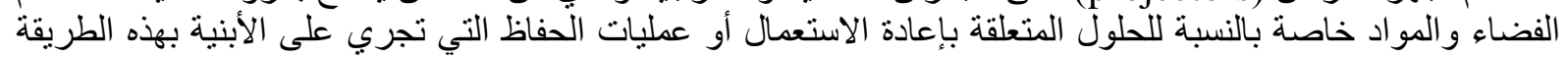

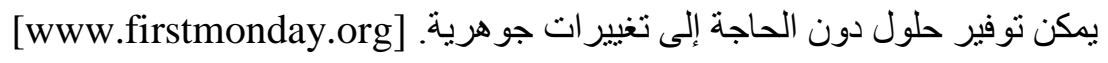

3 لمزيد من المعلومات حول هذه المادة وخو اصها راجع الر ابط التالي: www.architen.com/technical/articles/etfe-foil-a-guide-to-design 
بالنسبة للمظهر الأول من المرونة فان جميع تقنيات العمارة الإعلامية لها مرونة عالية في التبدل و التغير ومحتوى العرض لذا سيتم التركيز على المظهر الثناني فقط في هذه الدر اسة وكما يلي :

1 2

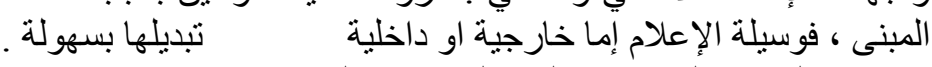

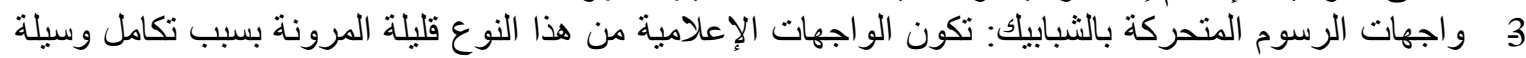

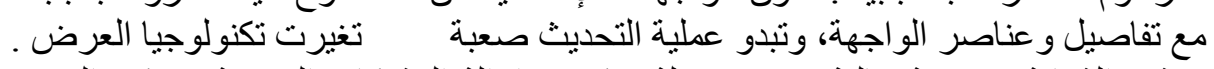

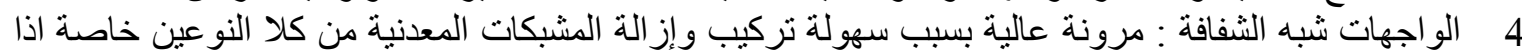

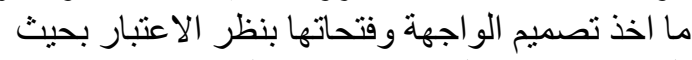

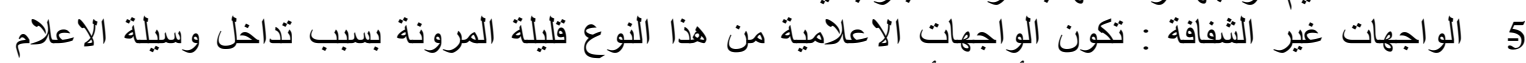

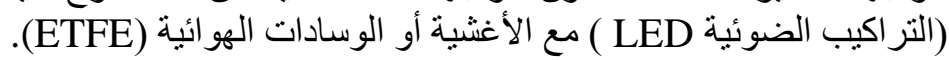

\section{البصرية:}

احد النقاط المهمة التي يمكن ان تثار عند تصميم الواجهات الإعلامية هي تعارض وظيفة هذه الواجهات مع نوفير

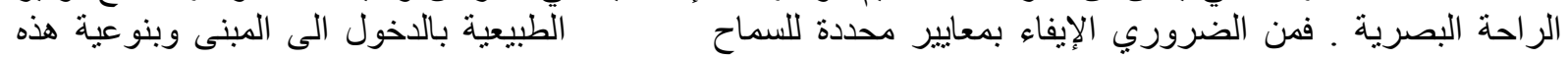

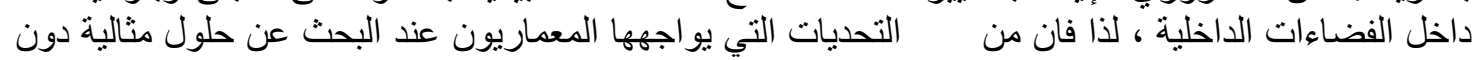

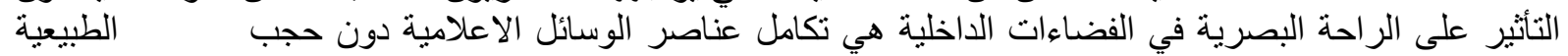

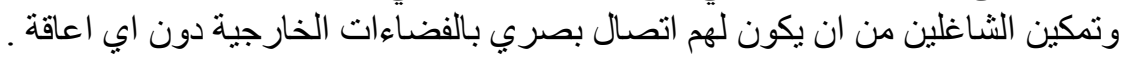

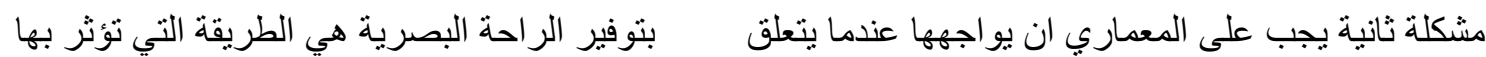

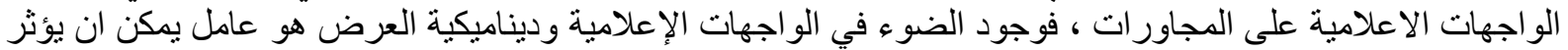

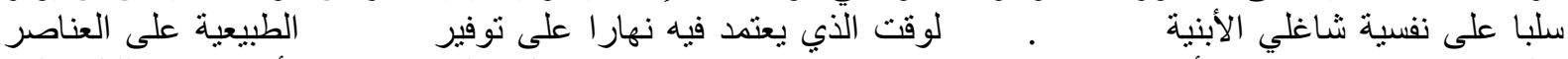

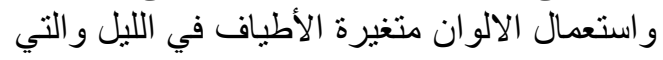

و المركبات الانعكاسية في الأبنية

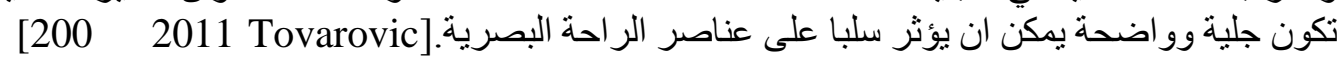

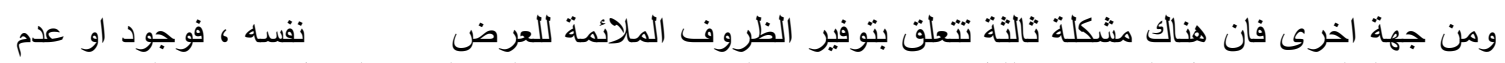

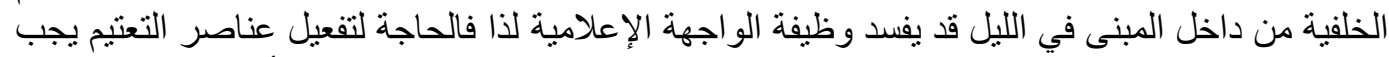

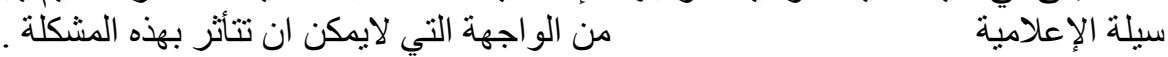

تقدم يمكن بيان الفروقات في تقنيات العمارة الإعلامية اعتمادا على توفير الراحة البصرية وكما

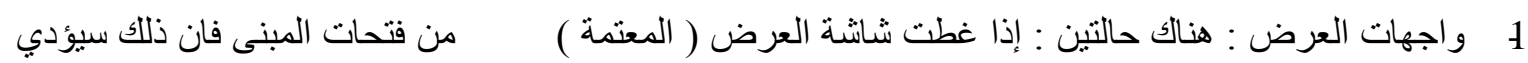

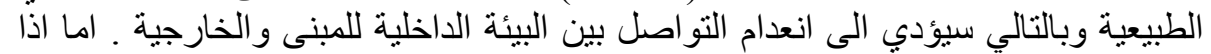

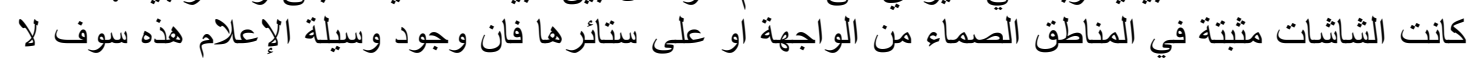

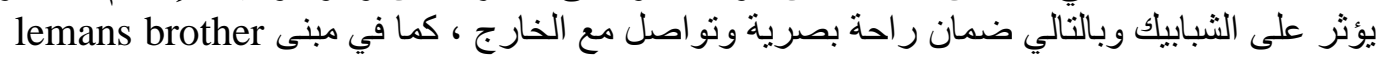

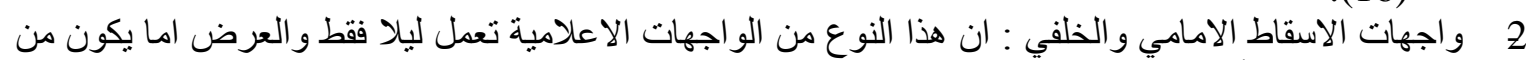

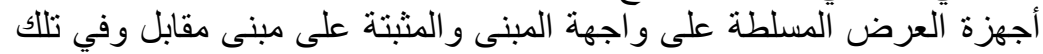

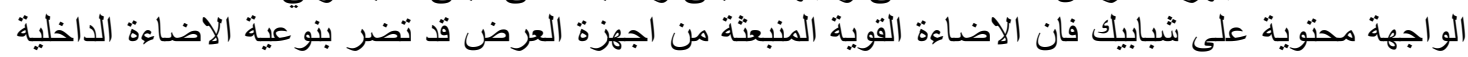

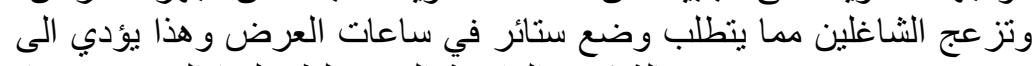

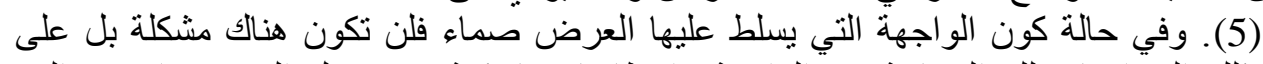

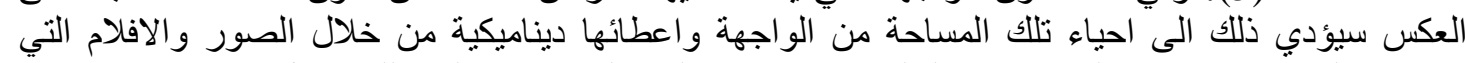

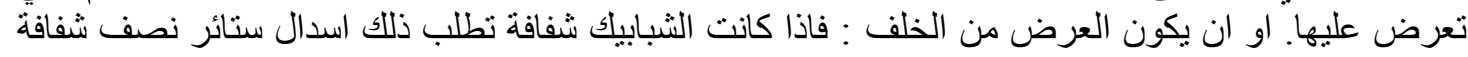

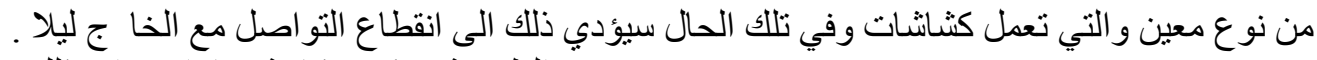

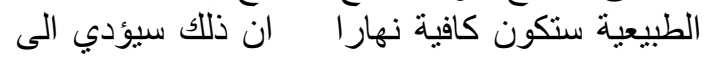

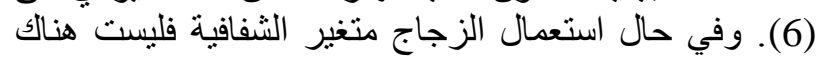




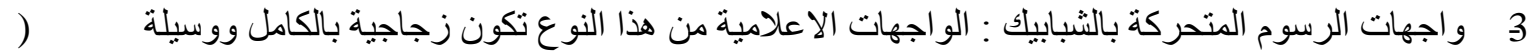

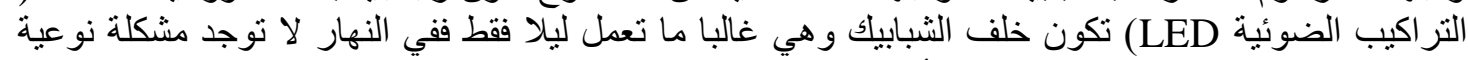

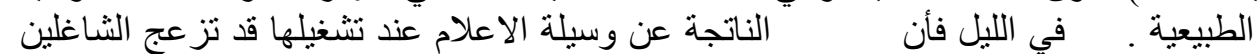

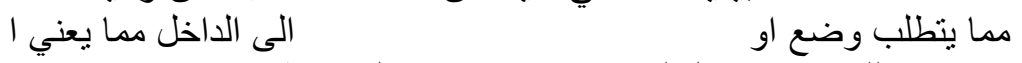

ان كانت تللك الابنية تشغل ليلا كما في مبنى شانيل في طوكيو. ( 18 )

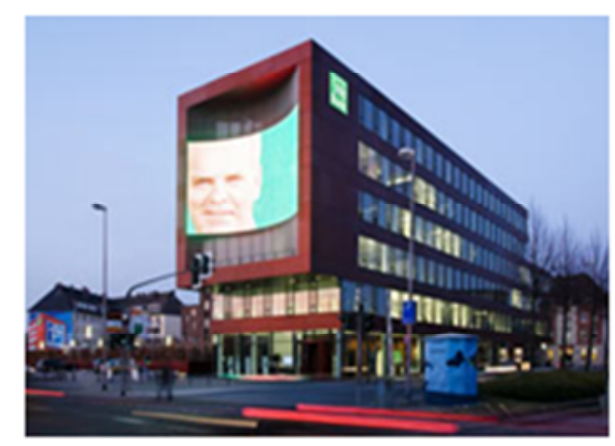

PSD

(19)

[www.munster.de]

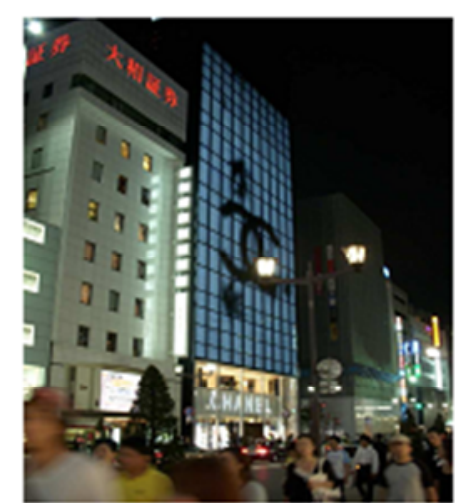

(18)

[25 2008 Tscherteu]

4 الواجهات شبه الثفافة : المشبكات المعدنية التي تتبت الواجهات الاعلامية من هذا النوع قد يقلل الثفافية

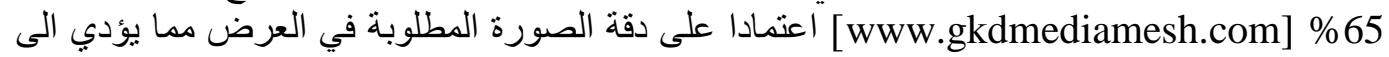

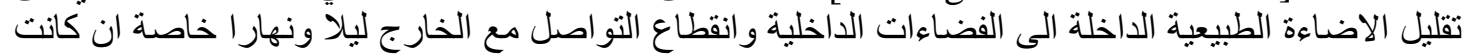

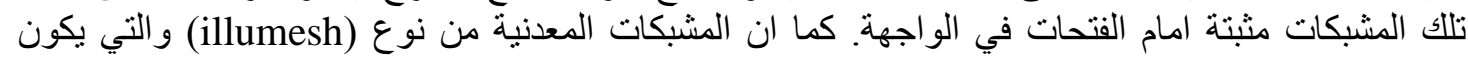

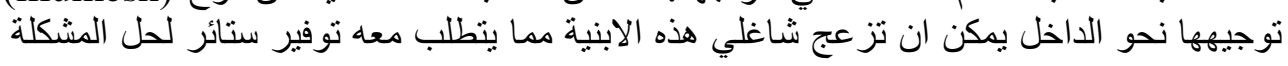
PSD

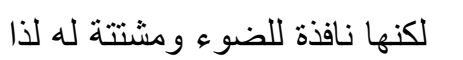
(ETFE) 5

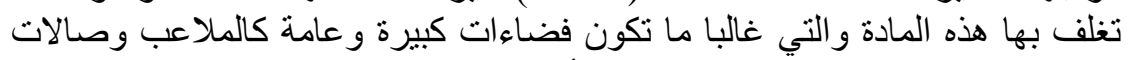

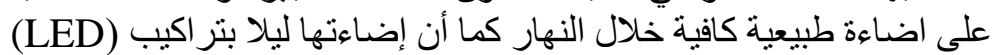

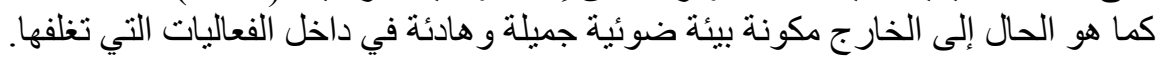

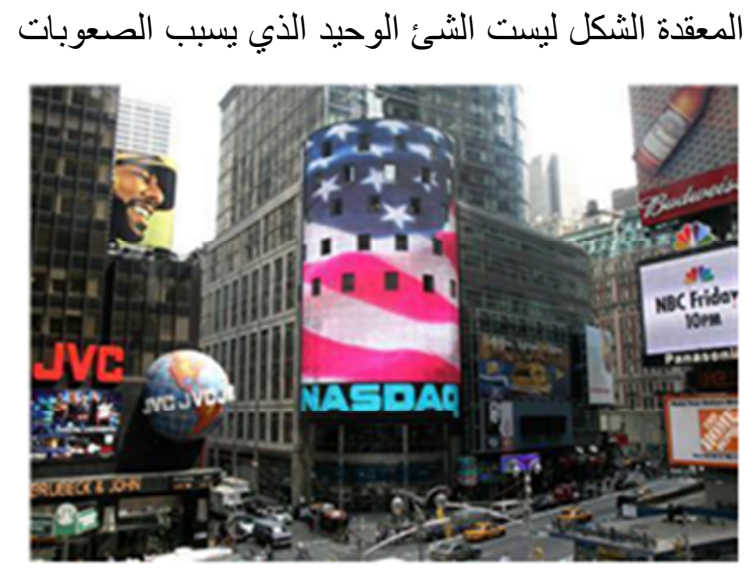

(20)

[3 2011 Wachlowski]

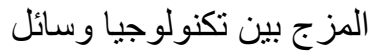

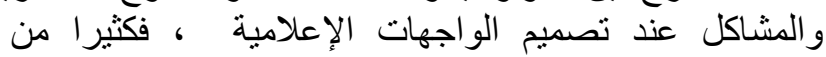
الثشاشات ليست قادل فادرة على الإيفاء بالاحتياجات الأساسية

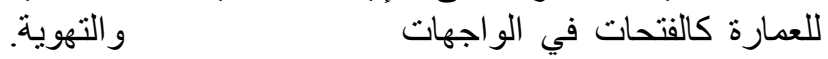

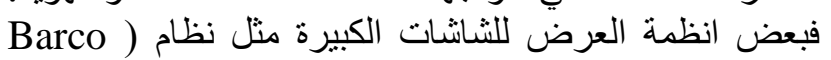

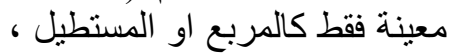
(olite

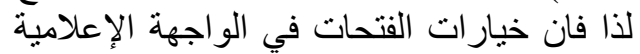

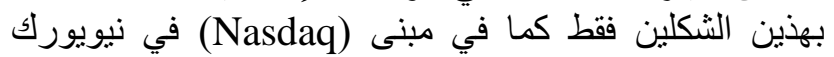

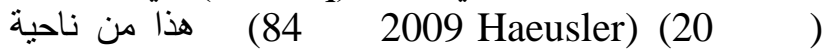

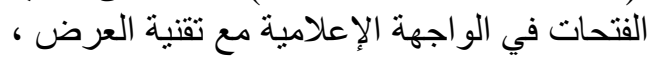

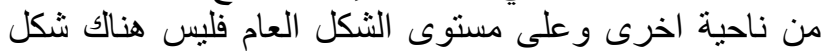

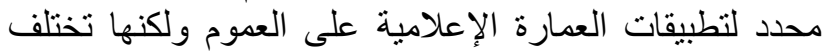

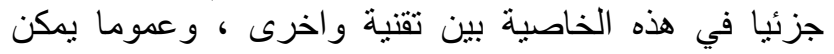
تحديد مظهرين لإشكال العمارة الإعلامية : تلنة (2D)

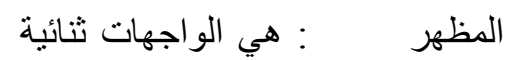


السمة السائدة في العمارة الإعلامية و اغلب الواجهات الإعلامية بمختلف تقنياتها هي من هذا النوع. وقد لا تتحدد الواجهة

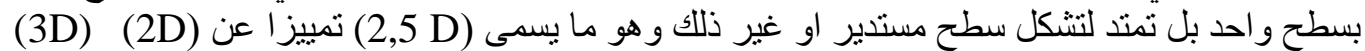

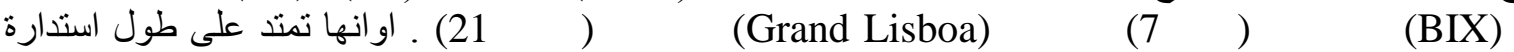
الهيكل البنائي كما في 2011 Tovarovic] (Galeria Store)

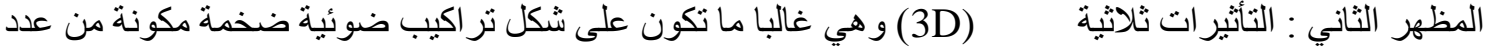

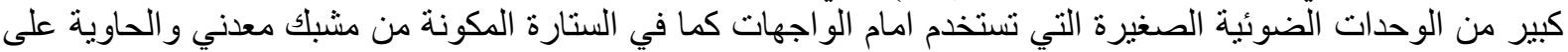

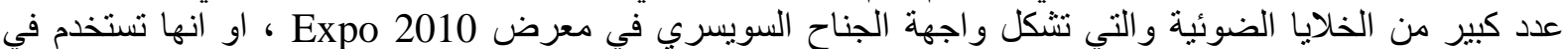

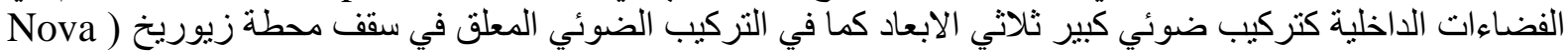
(system ومسيطر عليها بواسطة برمجيات (volumetric pixels) ملايين البكسلات الحجمية (Voxels) وهي (1)

[49 2008 Tscherteu] .

(3D)

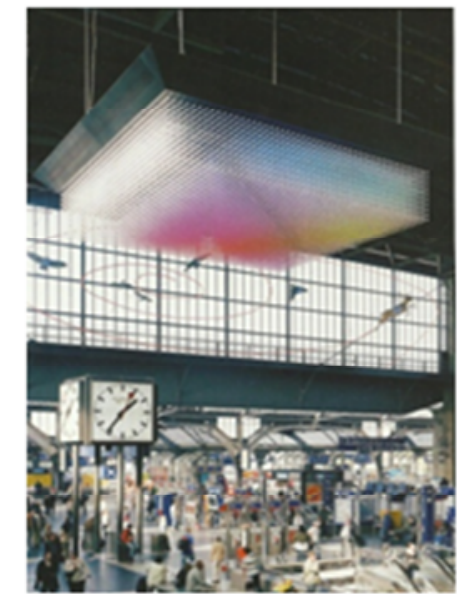

(22) التركيب الضوئي الثناثي الأبعاد

Nova system

[207 2009 Haeusler]

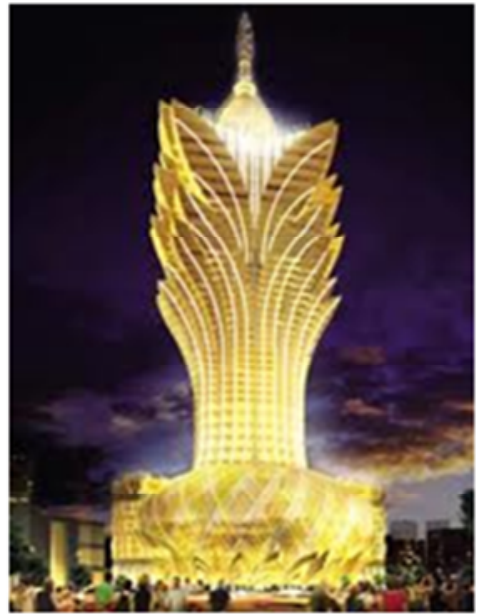

Grand lisboa

[www.heintges.com]

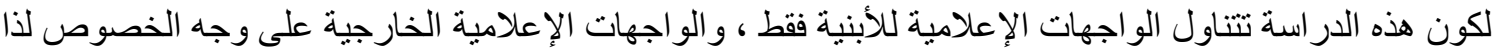

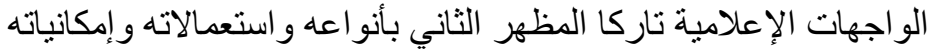

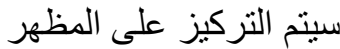
مستقبلية ان شاء الله.

ولإغر اض هذا البحث سيتم اعتماد التصنيف

1 2 3

لالتقنيات المختلفة للعمارة الإعلامية وكما يلي:

يمكن إظهار و على هذا

1 


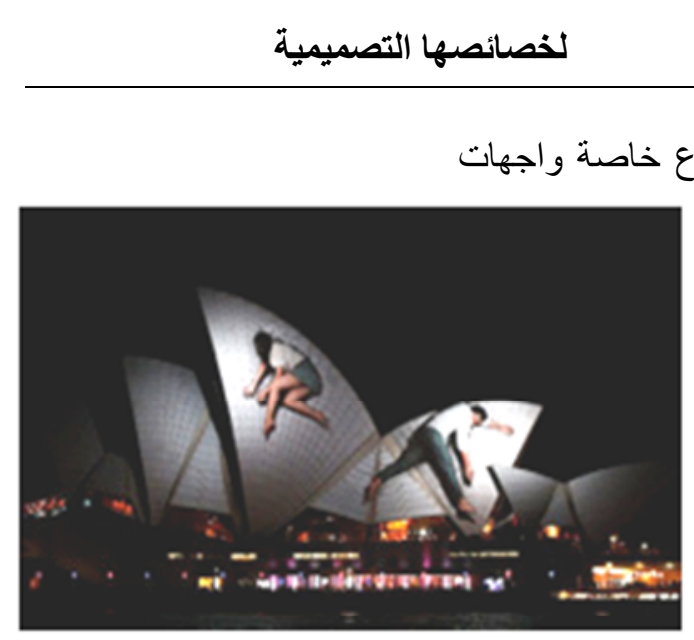

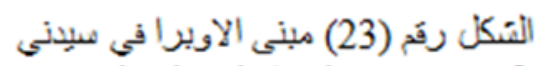

[www.whudat.de/sydney-opera-3d-] mapping-lighting

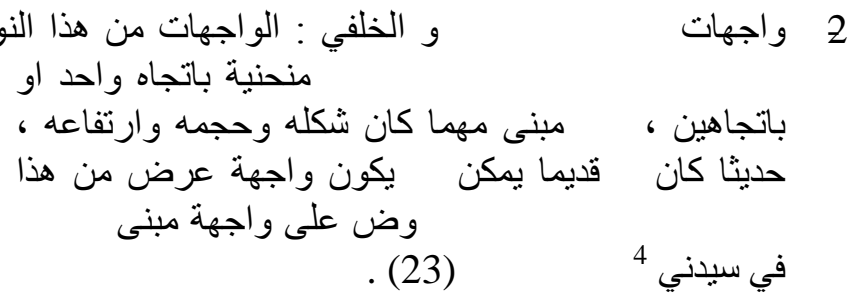

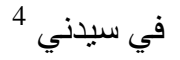

3

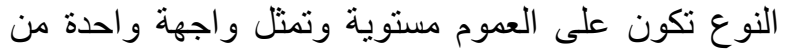

(Blinkenlights)

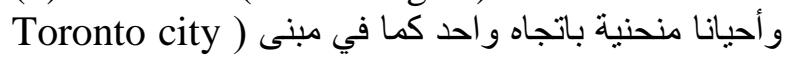

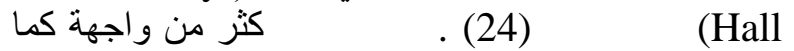

(10)

(Daxia Tower)

جزء معين فقط من الواجهة كما في مبنى (Spots)

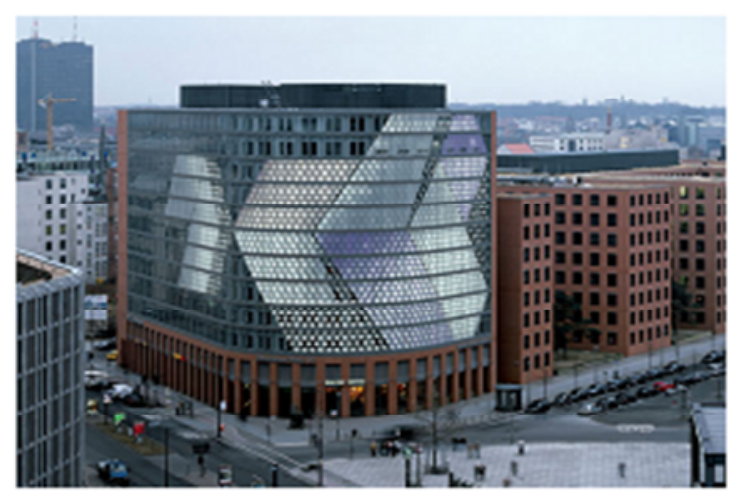

التنكل رقم (25) مبنى Spots في برلين

[115:ص،2010،Kronhagle]

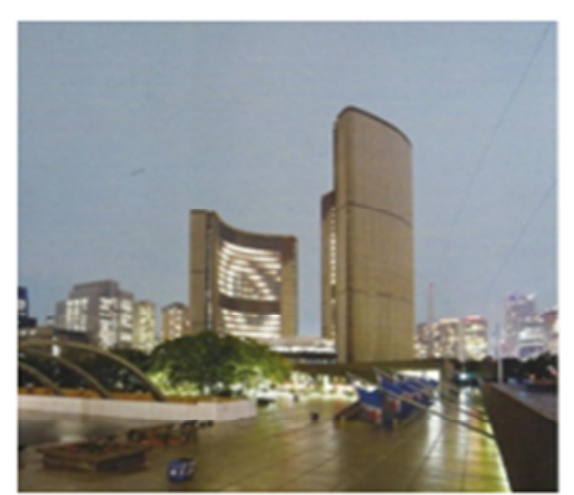

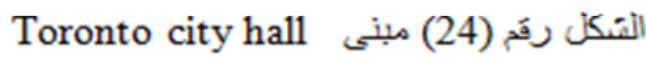
في كندا [112]:2009،Haeusler

4 الواجهات شبه الثفافة : الواجهات من هذا النوع تكون على العموم مستوية أيضا

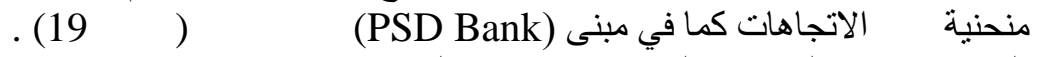
5 الأحادية يمكن يشكل منهاين (ETFE)

للغلاف الخارجي للمبنى مثال ذلك المكعب المائي في الصين ( الادية) .

$$
\text { : }
$$

مما تقدم يتبين وكما واضح من الجدول (3) ان هناك اختلافا بين بعض التقنيات الخمسة وفقا لكل خاصية

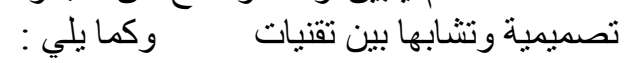

1

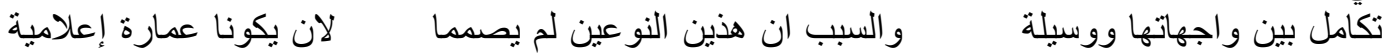

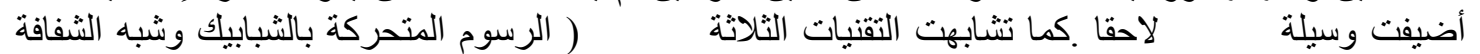

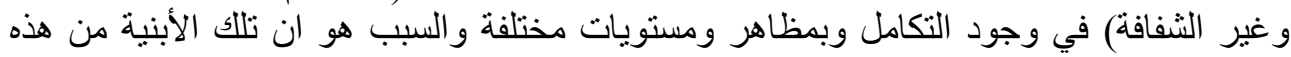
الهدف من تصميمها منذ البداية هو 


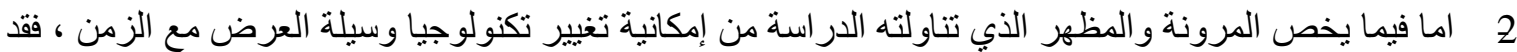

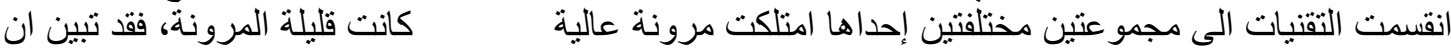

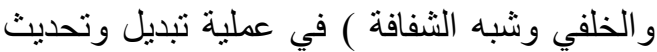

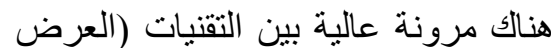

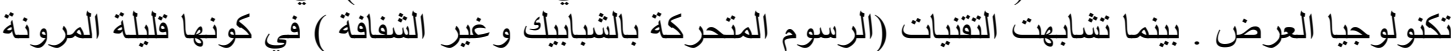

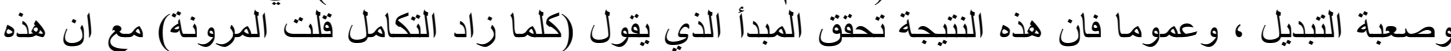

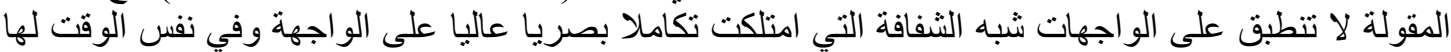
مرونة عالية في عملية التبديل. الئ.

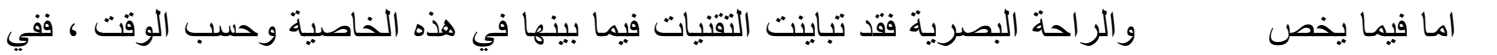

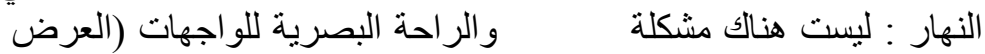

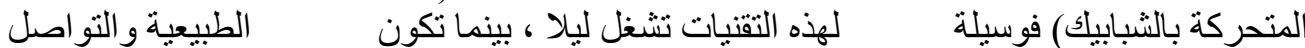
مشكلة في الواجهات شبه الثنفافة نهار ا بسبب وجود المشبكات المعدنية بينما تبدو المشكلة اقل تأثير ا في

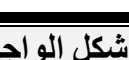

\begin{tabular}{|c|c|c|c|c|}
\hline شكل الواجهة & الإضاءة والراحة البصرية & & & نوع التقنية \\
\hline وأحيانا انحناء باتجاه & فإنحات المبنى (حجب الإضاءة الطبيعية & تبديل التكنولوجييً & لا بين وسيلة & واجهات العرض \\
\hline 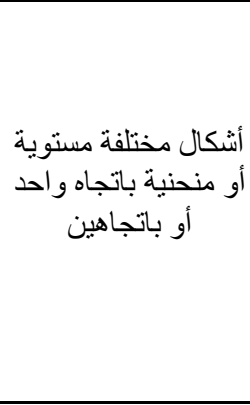 & 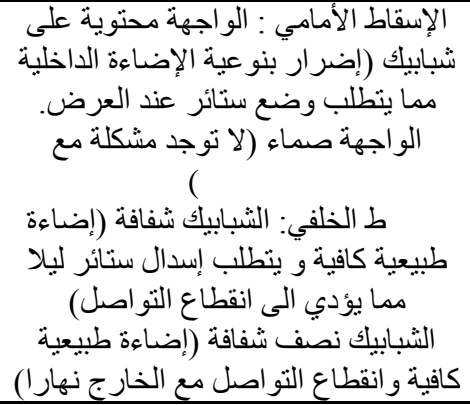 & تبديل التكنولوجية في & لا ين وجد تكامل & واجهات الإسقاط \\
\hline 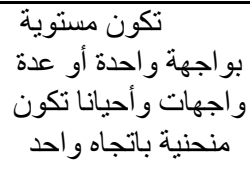 & 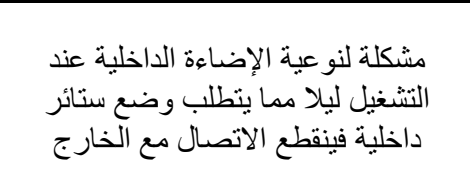 & وقلية التحرونة & تكامل فيزياوي & والتحركة النقطية \\
\hline و أحموانا منحنية باتجاه & مشكلة لنو عية الإضـاءة الداخلية ليلا ونهارا & سرونة عالية بسبب & & الواجهات شبه \\
\hline يمكن أن تكون بأي & إضاءة طبيعية جيلة نهارا وبيئة ضوئية & قليلة المرونة & & الواجهات غير \\
\hline
\end{tabular}

(3) يوضح تقنيات العمارة الاعلامية وخصائصها التصميمية (الباحث)

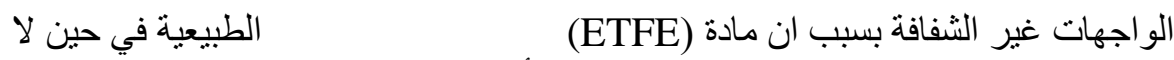

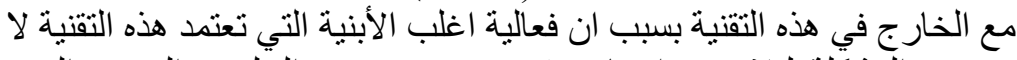

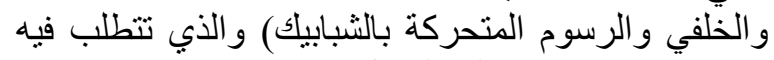

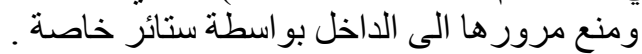

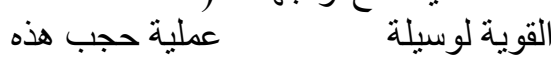




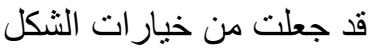
4 كانت الفعالية البنائية تصمم منذ البداية كعمارة إعلامية وبدائلة امر ا متاحا لكافة التقنيات خاصنة

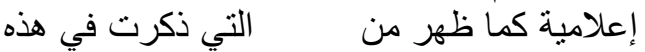
المنحنية و الملتوية المعقدة قدات التفات

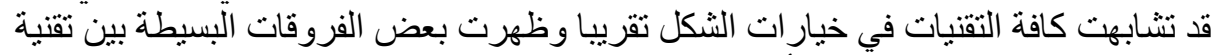

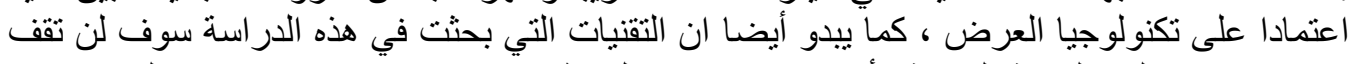

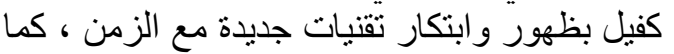

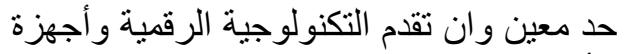

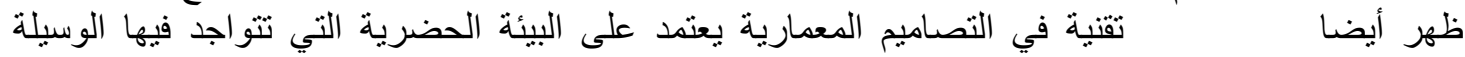
الإعلامية و على دقة العرض وضن ومحتوى وسيلة

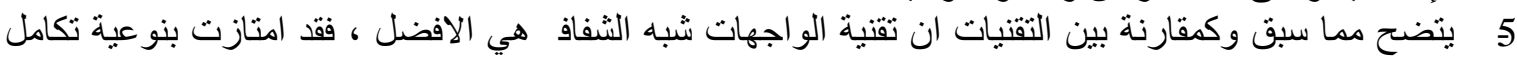

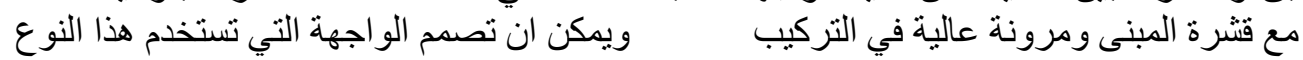

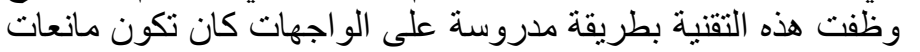
من التقنية

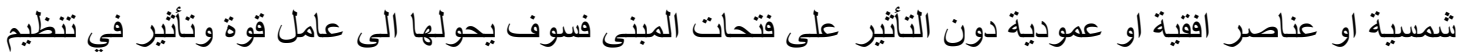
. تليها في ذلك تقنية

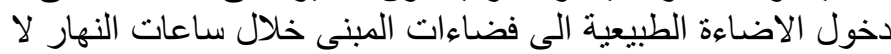

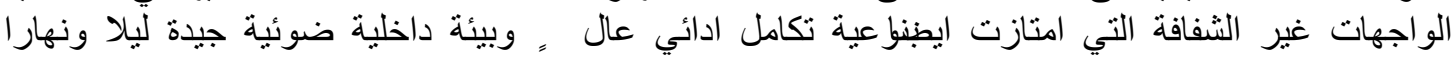

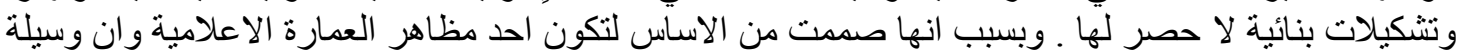

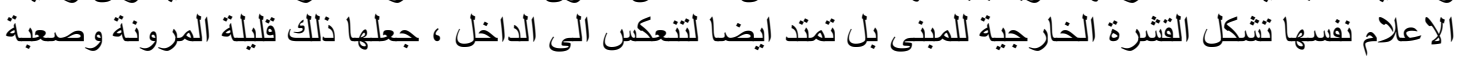
التحديث في حال تقادم التكنولوجيا التي تعمل بها.

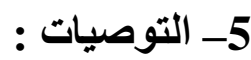

البحوث حول هذه الظاهرة المعمارية الحديثة وإمكانية تطبيقها في عمارتنا المحلية وبما

يحفظ الهوية الثقافية لإرثنا الحضاري والإفادة من عملية المقارنة بين التقنيات لتحديد الأنسب والناتية والأكفأ من هذه

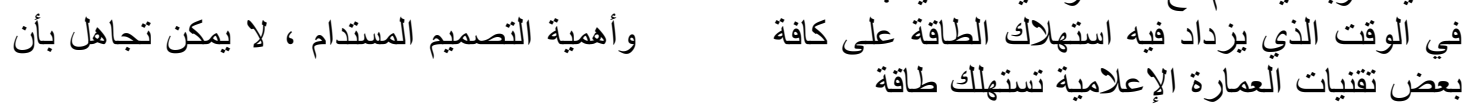

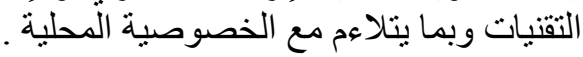

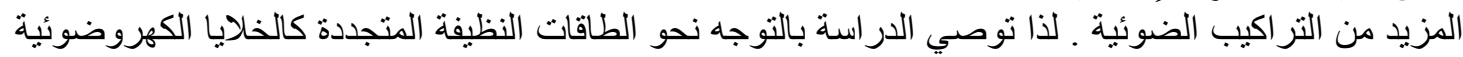
الإعلامية وعمل مزيد من البحوث حول هذا التوجه النظه

خلال عمليات ونتغيل

بنظر الاعتبار ديمومة القترة الخارجية للعمارة الإعلامية ومتانتها وتحملها للظروف الجوية الخارجية

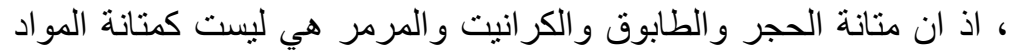

4 ألانهائية

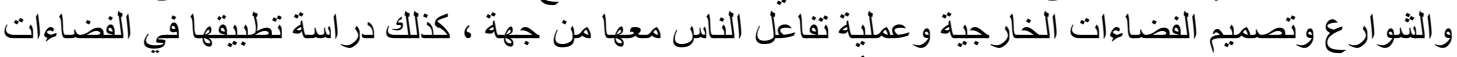

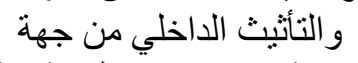

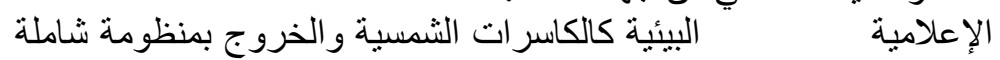

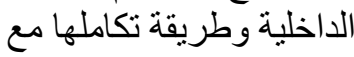

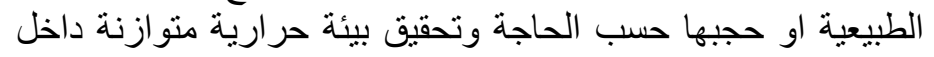
إمكانية نانة عملها كو اجهة إعلامية ليلا.

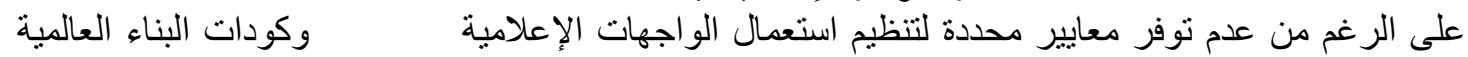

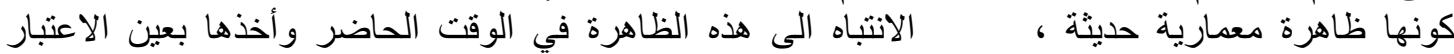

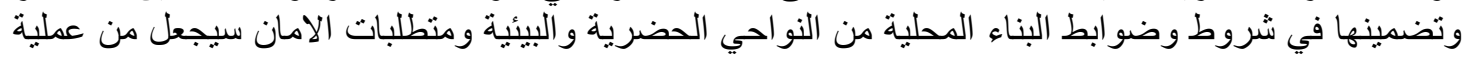
تطبيقها مستقبلا خاليا من السلبيات الى اقل حد ممكن.

1- Schiek, A.F. Towards an integrated architectural media space, First Monday, special issue \# 4 : Urban Screen : Discovering the potential of outdoor screens for urban society , 2006> http://firstmonday.org/ojs/index.php/fm/rt/printerfriendly/1550/1465.

2- Tovarovic , J. C. , Sekularac , N., Sekularac , J. I. , Specific Problems Of Media Façade Design , Facta universitatis, series : Architecture and Civil Engineering, vol. 9, No.1, 201, (p193- p203) 
3- Tscherteu , G. , Media Architecture , in Media architecture Biennale 2010 , edited by Tscherteu, G. ,Tmitsch , M. , Media Architecture institute , Vienna 2010 .

4- Wachlowski, A. , Interactive Media Facades In The Urban Context, master thesis in business administration, Modul University, Vienna , May 2011.

5- Moza , E.A. , From Advertising Architecture To Media façade , Communication through digital display Skin .

http://icaud.epoka.edu.al./res/1-icaud-papers/1icaud2012-esra-aydogan-moza.pdf.

6- Kronhagle, C. (ED). Mediatecture, The Design Of Medially Augmented Spaces , Springer Wien , New York, 2010.

7- Haeusler, M. H., Media Facades, History , Technology , Content, Avedition Gmbh , Ludwigsburg, Germany 2009.

8- Huhtamo , E. , Elements Of Screenology : Toward an Archeology Of The Screen , ICONICS : International Studies Of The Modern Image, Vol. 7 Tokyo (2007).

9- http://en.wikipedia.org./wiki/jumbotorn.

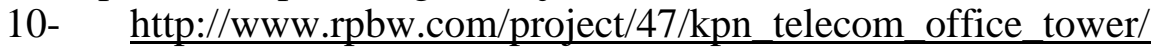

11- $\quad$ http://blinkelights.net/project.

12- $\quad$ http://www.medienaesthetik.de/medien/fassade.html.

13- Bachman, L. , Integrated Buildings , The System Basis Of Architecture , John Wiley \& Sons, Inc. Newgersey, USA. 2003.

14- Rush , R. D. , The Building Systems Integration Handbook, The American Institute Of Architecture, John Wiley \& Sons, New York , USA. 1986.

15- Tscherteu , G. , Leeb , D. , Media Façade : Fundamental Terms And Concepts, in Media Façade Exhibition, edited by Tscherteu , G. , German Center For Architecture , Berlin , Germany 2008.

16- Al-Nijaidi , H. R. , A Study Of The Relationship Between Change And Growth In Activity Pattern And The Physical Characteristics Of Buildings , M. phil. Thises . Oxford Polytechnic, in collaboration with Bartlett school of architecture and planning , UCL , Oxford 1982.

17- Fawcett, W. , Measuring Adaptability , Adaptability in The Design Of Building , Martin Center For Architectural and Urban Studies Tras. , Vol.1 , 1976.

18- Al-Nijaidi, H. R. , Flexibility In The Design Of Buildings , Ph.D. thesis , Oxford Polytechnic, Oxford, 1985.

19- GRD , Illumesh \& Mediamesh Transparent Media facades , pdf technical

Catalogue .

http://www.gkdmedia mesh.com.

20- Haeusler, M. H. Autonomous pixels : liberating The Pixel From Its Planar

Position On Screen, in Urban Screens Reader, edited by : Martin , M. Niederer , S. ,

Institute Of Network Cultures, Amsterdam, 2009.

21- http://www.heintges.com/project.php?id=grand_lisboa.

22- http://www.munster.de/stadt/galerie/dienstleistung_psd_bank.html.

23- www.seeingtheworld39.blogspot.com.

24- $\quad$ www.webdesignerdepot.com

25- www.wikimediacommons.com

26- www.mediafacade.net

27- www.whudat.de/sydney-opera-3d-mapping-lighting-the-sails-clip/

$$
\text { تم اجراء البحث في كلية الهندسة = }
$$

